\title{
Modeling the Impact of Hospital Logistics on Quality of Care and Patient Satisfaction: Results of a Survey in Three Public Healthcare Facilities in Fez - Morocco
}

\author{
Youness Frichi iD, Fouad Jawab iD, Said Boutahari iD \\ Industrial Technologies and Services, High School of Technology, Sidi Mohamed Ben Abdellab University (Morocco) \\ youness.frichi@usmba.ac.ma,fouad.jawab@usmba.ac.ma,boutahari@yahoo.fr
}

Received: February 2020

Accepted: March 2020

\section{Abstract:}

Purpose: The objective of this research is to examine the role of hospital logistics in improving quality of care and patient satisfaction. Thus, the paper focuses on modeling and evaluating the relationship between these three constructs.

Design/methodology/approach: In the present study, hospital logistics was specified as a second-order construct composed of five first-order constructs: physical accessibility, waiting time, consultation time, hospital hotel services, and administrative procedures. A questionnaire was developed and administered face-to-face to 384 hospitalized patients in three public healthcare facilities in Fez-Morocco. Collected data were processed and analyzed deploying the PLS-SEM method and using SmartPLS3 software. Data analysis was carried out by considering two types of patient circuits according to the admission modes in the healthcare facility: Urgent Patients Circuit and Scheduled Patients Circuit. Thus, two PLS-SEM models were evaluated and validated.

Findings: Results highlighted the significant impact of hospital logistics on quality and satisfaction. In particular, the results of the two models showed that the most preponderant hospital logistics component is physical accessibility which consists of the availability and accessibility of ambulances, medical and nursing staff, support and guidance staff, technical facilities and equipment, etc. Thus, hospital managers and health system stakeholders should pay particular attention to hospital logistics activities in general and specifically to the physical accessibility to improve the quality of care and patient satisfaction.

Research limitations/implications: This study only included patients from three public healthcare facilities in Fez-Morocco. Also, the model variables of hospital logistics construct are restricted and were applied in a specific context. Besides, the sample size was relatively reduced. Thus, results generalization might be limited. Further studies including more patients from other territories and including other logistics components are needed for large-scale validation of the proposed model.

Originality/value: The results of this study contribute to the scientific literature on hospital logistics and its role as a lever for quality of care and patient satisfaction.

Keywords: hospital logistics, quality of care, patient satisfaction, modeling, PLS-SEM, Morocco

\section{To cite this article:}

Frichi, Y., Jawab, F., \& Boutahari, S. (2020). Modeling the impact of hospital logistics on quality of care and patient satisfaction: Results of a survey in three public healthcare facilities in Fez - Morocco. Journal of Industrial Engineering and Management, 13(2), 296-320. https://doi.org/10.3926/jiem.3143 


\section{Introduction}

In 2015, Member States of the United Nations adopted the seventeen Sustainable Development Goals (SDGs) to be achieved by 2030. In particular, the SDG3 on health and well-being aims to improve the health status of individuals and promote access to quality care (United Nations, 2015). Morocco, as a member state of the United Nations, has implemented several health strategies, intending to provide quality and patient-centered healthcare services. In this context, Moroccan healthcare facilities are required to constantly improve the quality of care and enhance patient satisfaction. In that respect, hospital managers often focus the improvement efforts on reorganizing medical activities and show little interest in hospital logistics activities (Jobin, Beaulieu \& Boivin, 2004). This is because the primary goal of healthcare facilities is to provide care, therefore managers have historically looked at healthcare challenges through a clinical lens (Landry \& Philippe, 2004). However, several scholars have suggested looking at some of these challenges through the support services lens. They have highlighted the role of hospital logistics in helping healthcare facilities respond to health system challenges. In particular, hospital logistics is considered as a determining factor and lever for quality of care and patient satisfaction (Costin, 2010; Kriegel, Jehle, Dieck \& Mallory, 2013; Kwon, Kim \& Martin, 2016).

Hospital logistics is defined as a set of design, planning and execution activities that enable the purchase, inventory management and replenishment of goods and services surrounding the provision of medical services to patients (Landry \& Beaulieu, 2002). Studies agree that optimized hospital logistics enhances patient-centered care (Chow \& Heaver, 1994; Villa, Barbieri \& Lega, 2009). Indeed, some patient satisfaction studies have included logistics factors in their surveys and concluded the significant impact of these factors on quality and satisfaction levels. However, to the authors' knowledge, there is no research on the evaluation of logistics factors on quality and satisfaction in an integrated way (Frichi, Jawab \& Boutahari, 2019b). Hence a lack of clear and comprehensive evidence base that decision-makers could rely on to monitor the health system. Determining the extent of the contribution of hospital logistics to quality and patient's level of satisfaction is quite interesting considering the bunch of valuable information it will generate. Thus, the objective of this paper is to examine and confirm the positive impact of hospital logistics on quality of care and patient satisfaction.

The health system in Morocco is organized into two main sectors. The first is the public sector, made up of the healthcare services of the Ministry of Health, defense department and local authorities. The second is the private sector, which comprises the private for-profit sector, that includes hospital clinics, physicians' offices, dental surgery offices, pharmacies, etc., and the private not-for-profit sector, which encompasses health facilities of non-governmental organizations, Mutuals and National Fund of Social Security, Moroccan Red Crescent, etc. In this article, the focus is on the public health sector, particularly the healthcare services of the Ministry of Health, as they represent the bulk of the total healthcare offer, about $85 \%$ of the national hospital bed capacity (Bouhaddou, Bennani Othmani \& Diouny, 2013).

The remainder of this paper is structured as follows. Section 2 reviewed the literature on quality of care and patient satisfaction and their interactions with hospital logistics. It formulated the research hypotheses and the theoretical research model. Section 3 detailed the methodology for hypotheses assessment and validation. It consisted of a description of the healthcare facilities where the study was conducted, the participants included in the study, the questionnaire development and data analysis. Section 4 provided the research results while describing the various steps of model validation. Section 5 interpreted and discusses the obtained results. The last section concluded the paper and gave insights into future research.

\section{Background}

\subsection{Quality of Care and Patient Satisfaction}

Definitions of quality of care (QC) have been the subject of several studies in the literature. However, there no existing or likely consensus on a standardized definition (Nylenna, Bjertnaes, Saunes \& Lindahl, 2015). The American National Academy of Medicine defined QC as the degree to which health services for individuals and populations increase the likelihood of desired health outcomes, and are consistent with current professional knowledge (Lohr \& Schroeder, 1990). This definition underlined the clinical effectiveness of healthcare with the aim of improving the outcomes. These outcomes, according to Donabedian (2003), are the effects of healthcare on the population 
health status. Examples of healthcare outcomes are reduced mortality rates, restoration of function and survival, reduced hospital-acquired infections, improved patient satisfaction, etc. Furthermore, the QC should also reflect the wishes of health system stakeholders (Frichi, Jawab \& Boutahari, 2019c). On that point, some researchers have proposed to link QC to stakeholder satisfaction (Bautista \& Tangsoc, 2016), and particularly to the satisfaction of patients, as they are the most important stakeholder group in the health system (Frichi et al., 2019c; Symmank, Krause \& Gurtner, 2015).

Patient satisfaction (PS) is an assessment that reflects the patient's perceived differences between what is expected and what is received during the care process (Mohd \& Chakravarty, 2014). The measurement of PS is an essential element in the evaluation of QC (Derebe, Shiferaw \& Ayalew, 2017; Más, Parra, Bermejo, Hidalgo \& Calle, 2016). Indeed, the literature on the assessment of QC shows extensive use of PS measurement as an indicator of QC (Akachi \& Kruk, 2017; Frosch, 2015). Thus, we hypothesize that:

\section{H1: Quality of care (QC) influences positively patient satisfaction (PS).}

The goal of PS studies and surveys is to understand its associated factors, whose improvement could contribute to enhancing the quality of the healthcare system (Park, Park, Kwon, Kang \& Noh, 2016). Factors thought to be associated with PS include patient demographics and health characteristics (Soufi, Belayachi, Himmich, Ahid, Soufi, Zekraoui et al., 2010; Verulava, Jorbenadze, Karimi, Dangadze \& Barkalaia, 2018), healthcare workers attitude and behavior (Fang, Liu \& Fang, 2019), accessibility of care (Põlluste, Kallikorm, Meiesaar \& Lember, 2012), waiting time (Bleustein, Rothschild, Valen, Valaitis, Schweitzer \& Jones, 2014), consultation time (Howie, Porter, Heaney \& Hopton, 1991), administrative procedures (Mohamed \& Azizan, 2015), hospital hotel services (Sevin, 2018; Suess \& Mody, 2018), etc.

\subsection{Hospital Logistics and its Interaction with QC and PS}

Logistics is a rather diffuse function; it takes different forms that vary over time and context. In particular, hospital logistics (HL) has been defined in different ways in the literature. The French Association of Supply Chain and Logistics (ASLOG) defined HL as the management of the flow of patients, products, materials, services, and the related information to ensure quality and safety at a defined level of performance and efficiency, from the provider to the patient and, as appropriate, to the final destination (Beaulieu, Bentahar \& Benzidia, 2019). HL is concerned with the management of flows to produce and deliver healthcare effectively. The HL includes a wide range of ancillary and support activities necessary in providing healthcare. It comprises planning and scheduling activities, purchase and replenishment management, distribution of equipment and medical supplies to care units, patients and products transportation, information system management, facilities maintenance, waste management, production activities such as laundry, sterilization, and hospital kitchen, etc. (Beaulieu \& Venne, 2018; Jawab, Frichi \& Boutahari, 2018).

Given its critical aspect in the provision of healthcare as well as its broad scope of intervention, HL is a research area that attracts researchers worldwide. In fact, the literature reviews of Moons, Waeyenbergh and Pintelon (2019), Volland, Fügener, Schoenfelder and Brunner (2017), and Narayana, Kumar Pati and Vrat (2014) highlighted the extent of studies conducted in the field of logistics in the health sector. Some of these studies argued that HL has a crucial role in improving QC and PS (Frichi, Jawab, Boutahari, Zehmed, Moufad et al., 2018; Landry \& Philippe, 2004; Melo, 2012). Melo (2012) considered that logistics activities impact significantly the quality of healthcare provided. According to Landry and Philippe (2004), optimizing and reengineering healthcare logistics could bring new sources of effectiveness and efficiencies both in logistical and clinical terms. HL aims at ensuring smooth physical, information and financial flows, and reducing the waiting time by a timely provision of needed resources to meet demands of healthcare users as well as the healthcare system as a whole (Buntak, Kovačić \& Martinčević, 2019; Landry \& Philippe, 2004). For instance, the unavailability of supplies may postpone a planned surgical intervention and negatively impact the patient's health. Logistics services enable the necessary production factors (caregivers, medicines, medical devices, etc.) to be available, functional and accessible as needed at the point of care (Kriegel et al., 2013).

Several factors associated with PS such as physical accessibility, waiting time, consultation time, hospital hotel services, and administrative procedures are highly dependent on the effectiveness of logistics activities in hospitals 
(Azzi, Persona, Sgarbossa \& Bonin, 2013; Costin, 2010; Frichi, Jawab \& Boutahari, 2018). In the following we provided the main interactions between HL on one hand and QC and PS on the other:

Physical accessibility of healthcare (PA): it refers to geographically accessible healthcare, provided in settings where the necessary and adequate skills and resources are available and appropriate to medical needs (Munir, Hafeez, Rashid, Iqbal \& Javed, 2019; WHO, 2006). It is about the physical ease with which patients receive healthcare services. To attain favorable healthcare outcomes in terms of QC and PS, healthcare services should be combined with improvements in PA (Munir et al., 2019). The PA includes access to healthcare facilities, which means the availability of medical transportation and access to care within the healthcare facility, particularly in terms of the availability of human resources (doctors, nurses, laboratory technicians, etc.) and materials (drugs, medical supplies, technical equipment, etc.). Thus, the ease of PA contributes to enhancing PS and QC (Derebe et al., 2017; Verulava et al., 2018).

Waiting time (WT): is the time between the patient's arrival at the hospital and the consultation (Assefa, Mosse \& Hailemichael, Y., 2011). Some authors include in WT, post-consultation time when patients have to wait in order to retrieve their medical record and physician's note before leaving the healthcare facility (Johnson \& Russell, 2015). WT was considered as a dimension of PS and a critical component of QC (Bleustein et al., 2014). In most PS studies, long WT has been found frustrating to patients and a predictor of patient dissatisfaction (Abu-Odah, Abu Salah, El-Khateeb \& El-Nems, 2018; Hussain, Asif, Jameel \& Hwang, 2019). WT can result from several factors, including delays in intervention planning, poor organization, unclear and complex administrative procedures, large patient flows, unavailable resources to meet medical needs, etc. (Bleustein et al., 2014; Derebe et al., 2017).

Consultation time (CT): is the time that caregivers spend with the patient (Assefa et al., 2011). It is considered to be an important attribute of PS and QC. Long CT is associated with higher satisfaction (Bleustein et al., 2014). The CT can be shortened because caregivers spent a huge amount of their time managing administrative and logistics activities, organizing care units and recording patients' information, which reduces the available time for consultations (Howie et al., 1991). Therefore, it is necessary to free caregivers from these time-consuming logistics and administrative activities so as to devote more time to patients (Landry \& Beaulieu, 2013). Studies have estimated that a nurse spends between $30 \%$ and $34 \%$ of her time performing logistics and administrative activities (Lerebours, Saltel, Béthune-volters, Nallet, Bourdat, Vesin-etterlen et al., 2015). According to WHO, a rational division of tasks among health workers is an effective strategy for enhancing care accessibility and quality (WHO, 2012). For example, freeing caregivers from logistics activities would allow them to focus on their mission of providing healthcare and consequently giving more time to patients (Beaulieu, 2019).

Hospital hotel services (HHS): these cover the conditions under which patients are accommodated in hospitals, including catering, cleanliness, hotel comfort, etc. All of these conditions significantly affect the PS level (Chougrani \& Ouhadji, 2014; Halsdorfer, Blasquez, Bensoussan, Gentile, Collado, Viton et al., 2011; Marama, Bayu, Merga \& Binu, 2018). Thus, it is necessary to pay great attention to these hotel services. For instance, the catering activity requires an adapted supply system to guarantee fresh meals, as well as better coordination between the catering department and the health care teams to take into account the nutritional specificities of each patient. The cleaning activity is responsible for the cleanliness of the premises. It requires that cleaning articles are available in the right quantities and at the right places, as well as appropriate management of hospital waste. The hospital laundry provides services such as the cleaning of linen, towels and staff uniforms, which ensures the comfort and hygiene to hospitalized patients. For this reason, well-adapted logistics circuits are required for the definition of clean and dirty linen storage areas, transportation, operation scheduling (disinfection, washing, rinsing, and drying) (WHO, 2008).

Administrative procedures (AP): they include administrative formalities and procedures relating to patient admission, medical treatment, and discharge processes. The clarity and simplicity of AP are fundamental to PS (Duggirala, Rajendran \& Anantharaman, 2008; Mohamed \& Azizan, 2015). In contrast, complex and repetitive AP have been identified as one of the main causes of waiting times (Ahmad, Khairatul \& Farnaza, 2017). Information flows, in particular, AP can be optimized and simplified through the use of hospital information systems, which have a 
decisive effect on information availability and reliability (Benamirouche, 2015). The use of information systems allows the collection, sharing and use of patient data for better health care delivery (Parks, Wigand, Bennani Othmani, Serhier \& Bouhaddou, 2019).

All of the above PS factors fall within the scope of HL. Based on these facts, our research hypotheses state that HL impacts both PS and QC (Figure 1):

H2: Hospital logistics (HL) has a positive impact on quality of care (QC);

H3: Hospital logistics (HL) has a positive impact on patient satisfaction (PS).

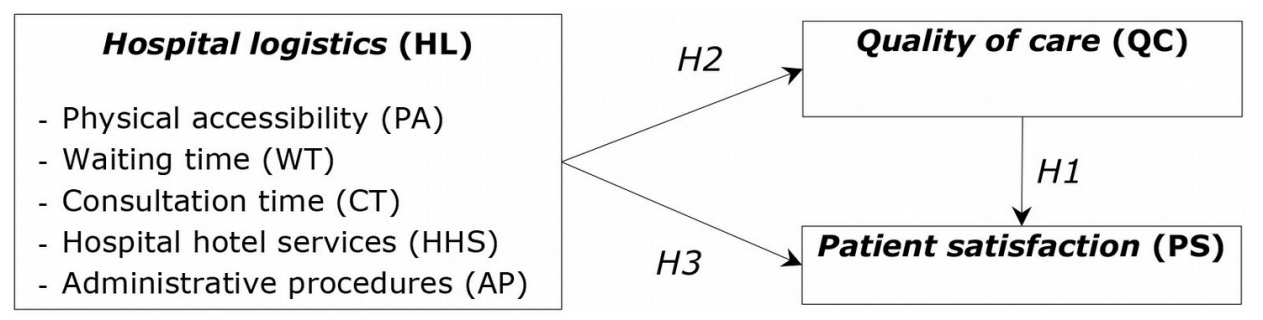

Figure 1. Hypothetical model

The hypotheses of the model in Figure 1 were supported and consolidated in an exploratory qualitative study in the form of semi-structured interviews with healthcare professionals and patients in the Moroccan context (Frichi, Jawab \& Boutahari, 2019a). The objective of the present study is to confirm empirically the hypothetical model with quantitative data.

In order to reduce the complexity of the model in Figure 1 and to test assumptions about the influence of HL on QC and PS, we modeled the variable HL as a second-order hierarchical reflective latent variable composed and measured by five first-order latent variables: PA, WT, CT, HHS and AP (Figure 2).

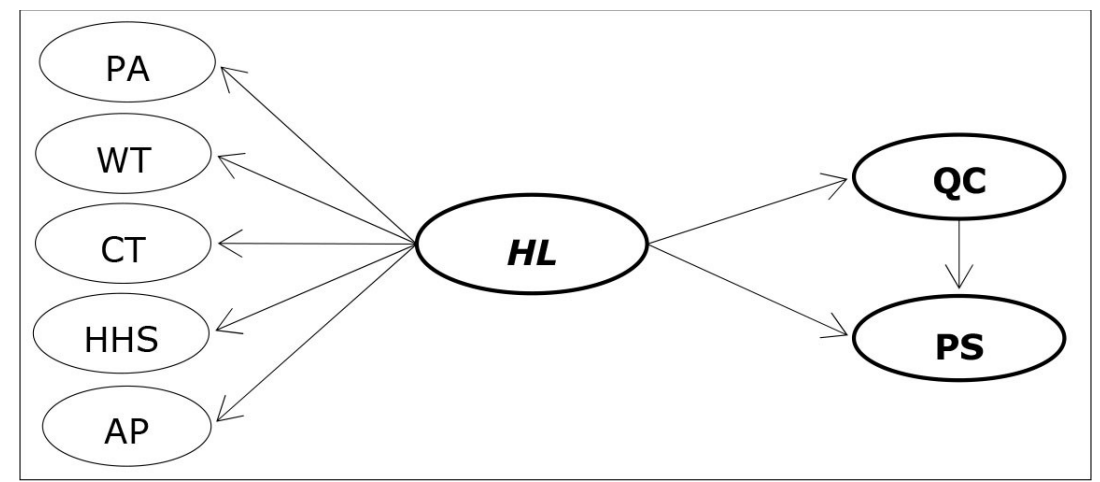

Figure 2. Theoretical model

The adopted method for hypotheses confirmation and validation is the Structural Equation Modelling (SEM), which tests statistically hypothetical correlation and causality relationships (Roussel \& Wacheux, 2005). This choice is justified by the objective of this research, which is to prove the correlation between HL, QC, and PS. Indeed, SEM is appropriate for modeling relationship systems, where correlations are hypothesized between a set of independent variables and dependent variables. In particular, SEM is recommended when key concepts are complex, multi-faceted, and difficult to measure (Kline, 2011). Also, SEM has known a wide application in the health and logistics sectors (Frichi et al., 2019b). As an indication, in the health sector, we cite (Schmalbach \& Avila, 2018; Al-Mhasnah, Salleh, Afthanorhan \& Ghazali, 2018; Jang \& Jang, 2017) and in the logistics sector (Moufad \& Jawab, 2019; Errassafi, Abbar \& Benabbou, 2019; De Carvalho, Kalid \& Rodriguez, 2019). 


\section{Methods}

\subsection{Settings}

This study was conducted in three public healthcare facilities in Fez-Morocco. These facilities account for almost all the public hospital care supply in the city of Fez. The characteristics of these healthcare facilities are described in Table 1.

\begin{tabular}{|l|r|r|}
\hline \multicolumn{1}{|c|}{ Healthcare facility } & Functional bedding capacity & \multicolumn{1}{|c|}{ Population served } \\
\hline Prefectural Hospital & 282 & 1427917 \\
\hline Regional Hospital & 250 & 4412905 \\
\hline University Hospital & 950 & 5961868 \\
\hline
\end{tabular}

Table 1. Study sittings' characteristics

\subsection{Participants}

The study participants are patients who had been hospitalized for at least 48 hours in one of the three healthcare facilities listed in Table 1. Thus, only patients who had experienced the entire process of the healthcare service and its related logistics activities are included in the survey. On the other hand, were excluded patients who had only benefited from outpatient care, patients under 18 years of age, and patients with acute physical and mental disabilities. The questionnaire was administered face-to-face to patients who met the inclusion criteria during the discharge process. The survey period was spread over 3 months from November 2019 to January 2020.

\subsection{Questionnaire Development}

The confirmation and validation of the theoretical model in Figure 1 consist of testing it with empirical data. For this reason, it is essential to have an instrument for measuring the model variables. To establish the measurement instrument, we have drawn inspiration from the paradigm suggested by Churchill (1979). The first step of the paradigm is to generate a sample of items capable to measure the variables. Through literature research, 56 items were generated. The second step deals with content validity, which assesses the degree to which the generated items capture the research constructs and are suitable for use in a survey. This step was carried out in two focus groups conducted sequentially. The first is made up of healthcare professionals from the Regional Hospital. It included the quality manager, the head of the medical affairs unit, the head of the nursing unit, and the head of the social care unit. The second focus group was organized with healthcare professionals of the Prefectural Hospital. It was composed of two nurses and a doctor. Focus groups participants were chosen based mainly on their experience and availability. At the end of the two focus groups, some items were judged inadequate and therefore deleted, or poorly formulated and therefore reformulated, while other items were grouped into a single item because they referred to similar aspects. On the other hand, some items were added by the participants.

It was noticed that some items are appropriate only for patients admitted through the emergency department, such as ambulance availability, while other items are more appropriate for scheduled patients, such as appointment delays. Accordingly, we decided to consider two patient circuits: Urgent Patients Circuit (UPC) and Scheduled Patients Circuit (SPC). Thus, the questionnaire questions are adapted according to the circuit type. The final results of the selected items are presented in Table 2. Constructs of PA, WT, and AP for the UPC were measured using items PAE1 to PAE15, WT1 to WT5 and APE1 to APE4 respectively. Similarly, the same constructs for the SPC were measured using items PAS1 to PAS12, WTS1 to WTS7 and APS1 to APS5. For the other model's constructs CT, HHS, QC, and PS, they were measured by items CT1, CT2, HHS1 to HHS13, QC1 to QC4, and SP1 to SP5 for both circuits UPC and SPC (Table 2).

The measurement scale adopted in this study is the Likert scale. Roussel and Wacheux (2005) recommended 5 -point scales when questionnaires are long (more than 60 items), and 7 or 9-point scales in the opposite case. Following these recommendations, we opted for a 7-point Likert scale ranging from "strongly agree (7)" to "strongly disagree (1)". 


\begin{tabular}{|c|c|c|c|c|}
\hline Variables & \multicolumn{3}{|l|}{ Items } & \multirow{2}{*}{$\begin{array}{l}\text { Sources } \\
\text { (Derebe et al., 2017) }\end{array}$} \\
\hline \multirow{15}{*}{ PA } & PAE1 & PAS1 & Time to reach the hospital & \\
\hline & PAE2 & PAS2 & Hospital geographic location & $\begin{array}{l}\text { (Lobo, Duarte, Carvalho, Rodrigues, } \\
\text { Monteiro \& Alves, 2014) }\end{array}$ \\
\hline & PAE3 & & Ambulance access & (Schmalbach \& Avila, 2018) \\
\hline & PAE4 & & Adequate number of ambulances & (Schmalbach \& Avila, 2018) \\
\hline & PAE5 & PAS3 & Availability of adequate parking & $\begin{array}{l}\text { (Badri, Dodeen, Al Khaili \& Abdulla, } \\
\text { 2005) }\end{array}$ \\
\hline & PAE6 & & Ease of access to the emergency department & Focus group results \\
\hline & PAE7 & PAS4 & Availability of support and guidance staff & Focus group results \\
\hline & PAE8 & PAS5 & $\begin{array}{l}\text { Lighting and clarity of patient lanes and } \\
\text { passageways }\end{array}$ & Focus group results \\
\hline & PAE9 & PAS6 & Signs and orientation panels & (Lobo et al., 2014) \\
\hline & PAE10 & PAS7 & Ease of access for persons with disabilities & Focus group results \\
\hline & PAE11 & PAS8 & $\begin{array}{l}\text { Availability of qualified and specialized doctors } \\
\text { and nurses }\end{array}$ & (Bautista \& Tangsoc, 2016) \\
\hline & PAE12 & PAS9 & $\begin{array}{l}\text { Availability and accessibility of technical } \\
\text { equipment and facilities }\end{array}$ & (Schmalbach \& Avila, 2018) \\
\hline & PAE13 & PAS10 & Availability of prescribed drug & (Marama et al., 2018) \\
\hline & PAE14 & PAS11 & Blood Availability & (Duggirala et al., 2008) \\
\hline & PAE15 & PAS12 & Overall physical accessibility of care & (Schmalbach \& Avila, 2018) \\
\hline \multirow{8}{*}{ WT } & & WTS1 & Appointment delays & (Dagger \& Sweeney, 2007) \\
\hline & & WTS2 & Waiting time for registration & (Nottingham, Johnson \& Russell, 2018) \\
\hline & & WTS3 & Waiting time for medical consultation & (Nottingham et al., 2018) \\
\hline & WT1 & & Waiting time in the emergency department & Focus group results \\
\hline & WT2 & WTS4 & $\begin{array}{l}\text { Waiting time for medical tests and radiological } \\
\text { examinations }\end{array}$ & (Duggirala et al., 2008) \\
\hline & WT3 & WTS5 & $\begin{array}{l}\text { Delays between discharge decision and effective } \\
\text { discharge }\end{array}$ & $\begin{array}{l}\text { (Soares, Marinho, Fernandes, Moreira } \\
\text { Gonçalves, Camila-Dias, Gonçalves et } \\
\text { al., 2015) }\end{array}$ \\
\hline & WT4 & WTS6 & Information about any delays & (Nottingham et al., 2018) \\
\hline & WT5 & WTS7 & Overall assessment of waiting times & (Derebe et al., 2017) \\
\hline \multirow{2}{*}{$\mathrm{CT}$} & \multicolumn{2}{|l|}{ CT1 } & Amount of time the physicians spent with you & (Verulava et al., 2018) \\
\hline & \multicolumn{2}{|l|}{ CT2 } & Amount of time the nursing staff spent with you & (Duggirala et al., 2008) \\
\hline \multirow{7}{*}{ HHS } & \multicolumn{2}{|l|}{ HHS1 } & Cleanliness of waiting and consultation rooms & (Assefa et al., 2011) \\
\hline & \multicolumn{2}{|l|}{ HHS2 } & $\begin{array}{l}\text { Comfort of waiting and consultation rooms: air } \\
\text { conditioning, availability of chairs, etc. }\end{array}$ & (Abu-Odah et al., 2018) \\
\hline & \multicolumn{2}{|l|}{ HHS3 } & Availability of in-patient rooms and beds & Focus group results \\
\hline & \multicolumn{2}{|l|}{ HHS4 } & Cleanliness of patient rooms & (Marama et al., 2018) \\
\hline & \multicolumn{2}{|l|}{ HHS5 } & $\begin{array}{l}\text { Patient rooms are well equipped: TV, shower, } \\
\text { clean towels, pillows, etc. }\end{array}$ & Focus group results \\
\hline & \multicolumn{2}{|l|}{ HHS6 } & $\begin{array}{l}\text { Comfort of the patients' rooms: air conditioning, } \\
\text { calm, beds in good repair, etc. }\end{array}$ & (Dagger \& Sweeney, 2007) \\
\hline & \multicolumn{2}{|l|}{ HHS7 } & Number of toilets and their accessibility & Focus group results \\
\hline
\end{tabular}




\begin{tabular}{|c|c|c|c|c|}
\hline Variables & \multicolumn{3}{|l|}{ Items } & Sources \\
\hline & \multicolumn{2}{|l|}{ HHS8 } & $\begin{array}{l}\text { Cleanliness of toilets: availability of toilet paper, } \\
\text { disinfectants, etc. }\end{array}$ & (Marama et al., 2018) \\
\hline & \multicolumn{2}{|l|}{ HHS9 } & The smell in the hospital & Focus group results \\
\hline & \multicolumn{2}{|l|}{ HHS10 } & Quality of meals & (Halsdorfer et al., 2011) \\
\hline & \multicolumn{2}{|l|}{ HHS11 } & Quantity of meals & Focus group results \\
\hline & \multicolumn{2}{|l|}{ HHS12 } & Freshness and hygiene of meals & Focus group results \\
\hline & \multicolumn{2}{|l|}{ HHS13 } & Respect for meal delivery times & Focus group results \\
\hline \multirow{5}{*}{ AP } & & APS1 & Ease of getting appointments & (Verulava et al., 2018) \\
\hline & APE1 & APS2 & $\begin{array}{l}\text { Clarity and ease of the admission administrative } \\
\text { process }\end{array}$ & (Marama et al., 2018) \\
\hline & APE2 & APS3 & Clarity and ease of payment procedure & (Badri et al., 2005) \\
\hline & APE3 & APS4 & Clarity and ease of discharge procedure & (Dagger \& Sweeney, 2007) \\
\hline & APE4 & APS5 & Overall hospital administrative procedure & (Um \& Lau, 2018) \\
\hline \multirow{4}{*}{ QC } & \multicolumn{2}{|l|}{ QC1 } & Excellence of care provided & (Soares et al., 2015) \\
\hline & \multicolumn{2}{|l|}{ QC2 } & $\begin{array}{l}\text { Extent to which the care provided is of high } \\
\text { standards }\end{array}$ & (Um \& Lau, 2018) \\
\hline & \multicolumn{2}{|l|}{ QC3 } & $\begin{array}{l}\text { Extent to which the quality of care at this hospital } \\
\text { is good in comparison with other hospitals }\end{array}$ & (Duggirala et al., 2008) \\
\hline & \multicolumn{2}{|l|}{ QC4 } & Overall quality of care & (Schmalbach \& Avila, 2018) \\
\hline \multirow{5}{*}{ PS } & \multicolumn{2}{|l|}{ PS1 } & Fulfillment of needs and expectations & $\begin{array}{l}\text { (Aljaberi, Juni, Al-Maqtari, Lye, Saeed, } \\
\text { Al-Dubai et al., 2018) }\end{array}$ \\
\hline & \multicolumn{2}{|l|}{ PS2 } & Likelihood of recommending this hospital & (Johnson \& Russell, 2015) \\
\hline & \multicolumn{2}{|l|}{ PS3 } & Likelihood of choosing the same hospital & (Badri, Attia \& Ustadi, 2009) \\
\hline & \multicolumn{2}{|l|}{ PS4 } & Proximity of this hospital to an ideal hospital & $\begin{array}{l}\text { (Kashkoli, Zarei, Daneshkohan \& } \\
\text { Khodakarim, 2017) }\end{array}$ \\
\hline & \multicolumn{2}{|l|}{ PS5 } & Overall satisfaction & (Aljaberi et al., 2018) \\
\hline
\end{tabular}

Table 2. Questionnaire items

\subsection{Data Analysis}

For the evaluation and validation of the proposed model, we used the SEM. There are two SEM approaches for estimating model parameters: PLS-SEM and CB-SEM. The PLS-SEM technique can be used in explanatory and predictive research. It is suitable for complex models for which the theory is not sufficiently developed. Also, PLS-SEM does make no data distributional assumptions and can be used for a small sample size. As for the CB-SEM technique, it is used in explanatory research. It requires a normal data distribution and a large sample size (Hair, Hult, Ringle \& Sarstedt, 2017). Schmalbach and Avila (2018) used the two approaches PLS-SEM and CB-SEM for validating their model on the evaluation of citizens' satisfaction regarding healthcare services' quality. The authors validated the applicability of the two approaches to their research model. Nevertheless, they favored the PLS-SEM approach, since it presented advantages over the CB-SEM approach, notably the flexibility in its application in the social science area, where data are usually not normally distributed, and the sample size is small. Hence, and following the recommendations of Hair et al. (2017), we opted for the PLS-SEM approach for the estimation of the model parameters. The data collected through the survey were processed using SmartPLS3 software.

\subsection{Sample}

The sample size for this study was calculated based on the rule of thumb for PLS-SEM model estimation parameters proposed by Barclay, Higgins and Thompson (1995). The rule of thumb specified that the minimum 
sample size is 10 times the maximum number of manifest variables of any latent variable in the measurement model, and 10 times the maximum number of paths aiming at any latent variable.

In the UPC model, the latent variable with the largest number of manifest variables is the PA, which has 15 manifest variables. For the SPC model, the largest number of manifest variables is 13 corresponding to the HHS. According to the rule of Barclay et al. (1995), a minimum of 150 participants for the first circuit and 130 for the second are required.

\subsection{Ethical Approval}

The conduct of this study in the above-mentioned hospitals was approved by the decision of the Fez-Meknes Regional Health Directorate No. 7579/SRHC/UGC3.

\section{Results}

\subsection{Participants Characteristics}

Four hundred thirty-seven patients were approached, 53 of them refused to participate because of a lack of time or unwillingness to take part in the study. Thus, 384 patients were included in the study, of which 242 (63\%) were women and $142(37 \%)$ men. The number of patients admitted through the emergency department was 235 $(61.20 \%)$ and $149(38.80 \%)$ were scheduled patients. Most of the participants $(45.57 \%)$ were young people between 25 and 34 years of age. Residents of cities represented $61.20 \%$ of the respondents, those living in villages and remote areas represented $21.87 \%$ and $16.93 \%$ respectively. Nearly $50 \%$ of the surveyed population had a lower level of education. $26 \%$ of surveyed patients were hospitalized in the Prefectural Hospital, 37.24\% in the Regional Hospital and $36.72 \%$ in the University Hospital. In terms of monthly income, 45.31\% earned less than 260 USD, $24 \%$ had an income between 260 and 600 USD, and 17.54\% between 600 and 1000 USD per month. As for the type of medical coverage, 35.42\% had RAMED assurance, $25.52 \%$ CNOPS, $14.06 \%$ CNSS, 3.65\% other types, and $21.35 \%$ had no coverage (Table 3).

Data normal distribution was checked by skewness and kurtosis tests. For normally distributed data, skewness values should be between +1 and -1 , and kurtosis values should be less than +1 (Hair et al., 2017). The application of these tests revealed that our data distribution was not normal.

\begin{tabular}{|c|c|c|c|}
\hline Variable & Type & Frequency & $\%$ \\
\hline \multirow{2}{*}{ Sex } & Women & 242 & 63.02 \\
\hline & Men & 142 & 36.98 \\
\hline \multirow{2}{*}{ Type of admission } & Emergency department & 235 & 61.20 \\
\hline & Scheduled patient & 149 & 38.80 \\
\hline \multirow{5}{*}{ Age (year) } & {$[18-24]$} & 82 & 21.35 \\
\hline & {$[25-34]$} & 175 & 45.57 \\
\hline & {$[35-44]$} & 68 & 17.70 \\
\hline & {$[45-59]$} & 33 & 8.59 \\
\hline & Above 60 & 26 & 6.77 \\
\hline \multirow{3}{*}{ Residence area } & City & 235 & 61.20 \\
\hline & Village & 84 & 21.87 \\
\hline & Remote region & 65 & 16.93 \\
\hline \multirow{4}{*}{ Leve of education } & Primary & 191 & 49.74 \\
\hline & Secondary & 98 & 25.52 \\
\hline & $\mathrm{Bac}$ and $\mathrm{Bac}+5$ & 60 & 15.62 \\
\hline & $\mathrm{bac}+5$ and above & 35 & 9.11 \\
\hline
\end{tabular}




\begin{tabular}{|c|c|c|c|}
\hline Variable & Type & Frequency & $\%$ \\
\hline \multirow{5}{*}{ Income (USD) } & Less than 260 & 174 & 45.31 \\
\hline & {$[260-600]$} & 92 & 23.96 \\
\hline & ] $600-1000]$ & 67 & 17.45 \\
\hline & ]1000 - 1500] & 39 & 10.15 \\
\hline & Above 1500 & 12 & 3.12 \\
\hline \multirow{3}{*}{ Healthcare facility } & Prefectural hospital & 100 & 26.04 \\
\hline & Regional hospital & 143 & 37.24 \\
\hline & University hospital & 141 & 36.72 \\
\hline \multirow{5}{*}{ Healthcare coverage } & RAMED & 136 & 35.42 \\
\hline & CNOPS & 98 & 25.52 \\
\hline & CNSS & 54 & 14.06 \\
\hline & Other & 14 & 3.65 \\
\hline & None & 82 & 21.35 \\
\hline
\end{tabular}

Table 3. Participants' socio-demographic characteristics

\subsection{Model Assessment and Validation}

As indicated earlier, we distinguished between two types of patient circuits depending on the admission type. Thus, we have considered two models: the UPC model and the SPC model. The two models were evaluated separately following guidelines and criteria recommended by Hair, Risher, Sarstedt and Ringle (2019).

\subsubsection{Measurement Model}

The assessment of the measurement model with reflective indicators consisted of checking indicators reliability, internal consistency reliability, convergent validity, and discriminant validity (Sarstedt \& Cheah, 2019).

Indicators reliability: The first step in evaluating the measurement model is to check the reliability of each manifest variable by examining its factor loading in the latent variable. It is recommended that only items with factor loadings greater than 0.708 be retained (Hair et al., 2019). Therefore, in the UPC model, 8 items of the latent variable PA and 5 items of the variable HHS, as well as one item of the variable WT, were eliminated. Similarly, in the SPC model, 7 items of the variable PA, 6 items of the variable HHS and one item of the variable WT were removed, because their loadings were lower than 0.708. Also, these items did not show significant factorial contributions with any of the other latent variables. Furthermore, it was observed that the elimination of these items increased the Average Variance Extracted (AVE) values. Retained items are reported in Table 4.

Internal consistency reliability: constructs internal consistency was assessed using Cronbach's alpha and composite reliability (CR). Higher values of Cronbach's alpha and CR, above 0.7 or 0.8 , generally indicate a high level of reliability (Meena \& Sarmah, 2012), but they should not be greater than the limit of 0.95 as recommended by Hair et al. (2017). The results of Cronbach's alpha and CR are satisfactory (Table 4).

Convergent and discriminant validity: the convergent validity of each bloc of items was examined using the AVE values, which must be greater than 0.5 (Table 4). Discriminant validity indicates the extent to which a construct is different from all the model other constructs (Raposo, Alves \& Duarte, 2009). It was evaluated by establishing the cross-loadings matrix, which consists of checking that the loading of each indicator in its latent variable is greater than all its loadings in the other latent variables of the model (Hair et al., 2017). Cross-loadings results are given in Table 5. All indicators did not show higher loadings in any other latent variable than in the one they intended to measure. 


\begin{tabular}{|c|c|c|c|c|c|c|c|c|c|c|}
\hline \multirow{2}{*}{ Variables } & \multicolumn{5}{|c|}{ UPC model } & \multicolumn{5}{|c|}{ SPC model } \\
\hline & Item & Loading & Cronbach $\alpha$ & CR & AVE & Item & Loading & Cronbach $\alpha$ & CR & AVE \\
\hline PA & $\begin{array}{c}\text { PAE3 } \\
\text { PAE4 } \\
\text { PAE7 } \\
\text { PAE11 } \\
\text { PAE12 } \\
\text { PAE13 } \\
\text { PAE15 }\end{array}$ & $\begin{array}{l}0.823 \\
0.855 \\
0.763 \\
0.770 \\
0.835 \\
0.729 \\
0.940\end{array}$ & 0.917 & 0.934 & 0.671 & $\begin{array}{c}\text { PAS4 } \\
\text { PAS8 } \\
\text { PAS9 } \\
\text { PAS10 } \\
\text { PAS12 }\end{array}$ & $\begin{array}{l}0.787 \\
0.882 \\
0.773 \\
0.778 \\
0.927\end{array}$ & 0.887 & 0.918 & 0.692 \\
\hline WT & $\begin{array}{l}\text { W'T1 } \\
\text { W'T2 } \\
\text { W'T4 } \\
\text { W'T5 }\end{array}$ & $\begin{array}{l}0.865 \\
0.859 \\
0.824 \\
0.911\end{array}$ & 0.888 & 0.923 & 0.749 & $\begin{array}{l}\text { WTS1 } \\
\text { WTS2 } \\
\text { WTS3 } \\
\text { WTS4 } \\
\text { WTS6 } \\
\text { WTS7 }\end{array}$ & $\begin{array}{l}0.779 \\
0.868 \\
0.855 \\
0.863 \\
0.798 \\
0.889\end{array}$ & 0.918 & 0.936 & 0.710 \\
\hline CT & $\begin{array}{l}\text { CT1 } \\
\text { CT2 }\end{array}$ & $\begin{array}{l}0.900 \\
0.924\end{array}$ & 0.799 & 0.908 & 0.832 & $\begin{array}{l}\text { CT1 } \\
\text { CT2 }\end{array}$ & $\begin{array}{l}0.905 \\
0.924\end{array}$ & 0.806 & 0.911 & 0.837 \\
\hline HHS & $\begin{array}{l}\text { HHS3 } \\
\text { HHS4 } \\
\text { HHS5 } \\
\text { HHS6 } \\
\text { HHS9 } \\
\text { HHS10 } \\
\text { HHS11 } \\
\text { HHS12 }\end{array}$ & $\begin{array}{l}0.796 \\
0.854 \\
0.733 \\
0.842 \\
0.812 \\
0.838 \\
0.722 \\
0.822\end{array}$ & 0.921 & 0.936 & 0.646 & $\begin{array}{l}\text { HHS1 } \\
\text { HHS3 } \\
\text { HHS4 } \\
\text { HHS6 } \\
\text { HHS7 } \\
\text { HHS9 } \\
\text { HHS10 }\end{array}$ & $\begin{array}{l}0.763 \\
0.740 \\
0.840 \\
0.776 \\
0.769 \\
0.836 \\
0.788\end{array}$ & 0.898 & 0.920 & 0.621 \\
\hline $\mathrm{AP}$ & $\begin{array}{l}\text { APE1 } \\
\text { APE2 } \\
\text { APE3 } \\
\text { APE4 }\end{array}$ & $\begin{array}{l}0.913 \\
0.877 \\
0.896 \\
0.899\end{array}$ & 0.918 & 0.942 & 0.803 & $\begin{array}{l}\text { APS1 } \\
\text { APS2 } \\
\text { APS3 } \\
\text { APS4 } \\
\text { APS5 }\end{array}$ & $\begin{array}{l}0.761 \\
0.875 \\
0.771 \\
0.833 \\
0.907\end{array}$ & 0.888 & 0.918 & 0.691 \\
\hline QC & $\begin{array}{l}\text { QC1 } \\
\text { QC2 } \\
\text { QC3 } \\
\text { QC4 }\end{array}$ & $\begin{array}{l}0.910 \\
0.887 \\
0.854 \\
0.908\end{array}$ & 0.913 & 0.938 & 0.792 & $\begin{array}{l}\text { QC1 } \\
\text { QC2 } \\
\text { QC3 } \\
\text { QC4 }\end{array}$ & $\begin{array}{l}0.877 \\
0.836 \\
0.799 \\
0.887\end{array}$ & 0.872 & 0.913 & 0.723 \\
\hline PS & $\begin{array}{l}\text { PS1 } \\
\text { PS2 } \\
\text { PS3 } \\
\text { PS4 } \\
\text { PS5 }\end{array}$ & $\begin{array}{l}0.857 \\
0.937 \\
0.884 \\
0.769 \\
0.947\end{array}$ & 0.927 & 0.945 & 0.777 & $\begin{array}{l}\text { PS1 } \\
\text { PS2 } \\
\text { PS3 } \\
\text { PS4 } \\
\text { PS5 }\end{array}$ & $\begin{array}{l}0.827 \\
0.843 \\
0.807 \\
0.823 \\
0.913\end{array}$ & 0.898 & 0.925 & 0.711 \\
\hline
\end{tabular}

Table 4. Individual item loadings, Cronbach $\alpha$, Composite reliability, and AVE

\begin{tabular}{|c|r|r|r|r|r|r|r|r|}
\hline \multicolumn{2}{|c|}{ PA } & WT & CT & HHS & AP & QC & PS \\
\hline \multicolumn{7}{|c|}{ UPC model } \\
\hline PAE3 & $\mathbf{0 . 8 2 3}$ & 0.640 & 0.481 & 0.492 & 0.661 & 0.511 & 0.552 \\
\hline PAE4 & $\mathbf{0 . 8 5 5}$ & 0.647 & 0.518 & 0.496 & 0.674 & 0.541 & 0.572 \\
\hline PAE7 & $\mathbf{0 . 7 6 3}$ & 0.647 & 0.422 & 0.490 & 0.584 & 0.522 & 0.569 \\
\hline PAE11 & $\mathbf{0 . 7 7 0}$ & 0.678 & 0.584 & 0.608 & 0.557 & 0.565 & 0.658 \\
\hline PAE12 & $\mathbf{0 . 8 3 5}$ & 0.710 & 0.513 & 0.599 & 0.679 & 0.563 & 0.571 \\
\hline PAE13 & $\mathbf{0 . 7 2 9}$ & 0.572 & 0.474 & 0.624 & 0.599 & 0.485 & 0.519 \\
\hline PAE15 & $\mathbf{0 . 9 4 0}$ & 0.788 & 0.639 & 0.651 & 0.745 & 0.689 & 0.732 \\
\hline WT1 & 0.648 & $\mathbf{0 . 8 6 5}$ & 0.437 & 0.514 & 0.571 & 0.476 & 0.553 \\
\hline
\end{tabular}




\begin{tabular}{|c|c|c|c|c|c|c|c|}
\hline & PA & WT & CT & HHS & $\mathbf{A P}$ & QC & PS \\
\hline WT2 & 0.741 & 0.859 & 0.520 & 0.588 & 0.694 & 0.490 & 0.547 \\
\hline WT4 & 0.656 & 0.824 & 0.409 & 0.501 & 0.612 & 0.466 & 0.503 \\
\hline WT5 & 0.783 & 0.911 & 0.482 & 0.552 & 0.655 & 0.535 & 0.606 \\
\hline CT1 & 0.517 & 0.440 & 0.900 & 0.602 & 0.448 & 0.674 & 0.617 \\
\hline CT2 & 0.639 & 0.533 & 0.924 & 0.621 & 0.538 & 0.648 & 0.648 \\
\hline HHS3 & 0.617 & 0.590 & 0.534 & 0.796 & 0.559 & 0.549 & 0.590 \\
\hline HHS4 & 0.570 & 0.506 & 0.630 & 0.854 & 0.475 & 0.637 & 0.634 \\
\hline HHS5 & 0.487 & 0.406 & 0.405 & 0.733 & 0.426 & 0.441 & 0.426 \\
\hline HHS6 & 0.682 & 0.642 & 0.564 & 0.842 & 0.615 & 0.588 & 0.618 \\
\hline HHS9 & 0.587 & 0.537 & 0.489 & 0.812 & 0.560 & 0.550 & 0.610 \\
\hline HHS10 & 0.519 & 0.470 & 0.571 & 0.838 & 0.506 & 0.642 & 0.657 \\
\hline HHS11 & 0.432 & 0.352 & 0.507 & 0.722 & 0.429 & 0.574 & 0.560 \\
\hline HHS12 & 0.520 & 0.459 & 0.597 & 0.822 & 0.463 & 0.642 & 0.617 \\
\hline APE1 & 0.723 & 0.678 & 0.447 & 0.533 & 0.913 & 0.472 & 0.480 \\
\hline APE2 & 0.623 & 0.581 & 0.435 & 0.553 & 0.877 & 0.538 & 0.485 \\
\hline APE3 & 0.648 & 0.605 & 0.503 & 0.562 & 0.896 & 0.566 & 0.507 \\
\hline APE4 & 0.812 & 0.750 & 0.555 & 0.613 & 0.899 & 0.578 & 0.584 \\
\hline QC1 & 0.586 & 0.474 & 0.674 & 0.619 & 0.526 & 0.910 & 0.747 \\
\hline QC2 & 0.555 & 0.456 & 0.589 & 0.564 & 0.479 & 0.887 & 0.740 \\
\hline QC3 & 0.574 & 0.490 & 0.574 & 0.656 & 0.521 & 0.854 & 0.713 \\
\hline QC4 & 0.692 & 0.592 & 0.724 & 0.713 & 0.604 & 0.908 & 0.850 \\
\hline PS1 & 0.641 & 0.531 & 0.649 & 0.616 & 0.511 & 0.835 & 0.859 \\
\hline PS2 & 0.694 & 0.619 & 0.608 & 0.688 & 0.560 & 0.791 & 0.937 \\
\hline PS3 & 0.646 & 0.580 & 0.578 & 0.650 & 0.543 & 0.697 & 0.883 \\
\hline PS4 & 0.563 & 0.506 & 0.484 & 0.559 & 0.377 & 0.561 & 0.767 \\
\hline PS5 & 0.671 & 0.582 & 0.710 & 0.720 & 0.525 & 0.845 & 0.948 \\
\hline \multicolumn{8}{|c|}{ SPC model } \\
\hline PAS4 & 0.787 & 0.577 & 0.635 & 0.446 & 0.527 & 0.540 & 0.536 \\
\hline PAS8 & 0.882 & 0.710 & 0.711 & 0.594 & 0.607 & 0.676 & 0.685 \\
\hline PAS9 & 0.773 & 0.600 & 0.542 & 0.504 & 0.497 & 0.492 & 0.540 \\
\hline PAS10 & 0.778 & 0.620 & 0.538 & 0.517 & 0.499 & 0.466 & 0.544 \\
\hline PAS12 & 0.927 & 0.724 & 0.680 & 0.554 & 0.630 & 0.699 & 0.711 \\
\hline W'TS1 & 0.590 & 0.779 & 0.420 & 0.364 & 0.526 & 0.450 & 0.446 \\
\hline WTS2 & 0.622 & 0.868 & 0.467 & 0.507 & 0.644 & 0.497 & 0.561 \\
\hline WTS3 & 0.623 & 0.855 & 0.444 & 0.430 & 0.614 & 0.428 & 0.507 \\
\hline W'TS4 & 0.708 & 0.863 & 0.488 & 0.481 & 0.542 & 0.514 & 0.550 \\
\hline W'TS6 & 0.617 & 0.798 & 0.445 & 0.493 & 0.542 & 0.363 & 0.437 \\
\hline W'TS7 & 0.771 & 0.889 & 0.538 & 0.560 & 0.648 & 0.550 & 0.650 \\
\hline CT1 & 0.651 & 0.483 & 0.905 & 0.509 & 0.473 & 0.552 & 0.536 \\
\hline CT2 & 0.718 & 0.532 & 0.924 & 0.585 & 0.558 & 0.623 & 0.618 \\
\hline HHS1 & 0.576 & 0.493 & 0.543 & 0.763 & 0.497 & 0.511 & 0.593 \\
\hline HHS3 & 0.591 & 0.519 & 0.494 & 0.740 & 0.564 & 0.502 & 0.552 \\
\hline HHS4 & 0.543 & 0.470 & 0.525 & 0.840 & 0.437 & 0.508 & 0.605 \\
\hline HHS6 & 0.440 & 0.455 & 0.381 & 0.776 & 0.306 & 0.366 & 0.504 \\
\hline
\end{tabular}




\begin{tabular}{|c|c|c|c|c|c|c|c|}
\hline & PA & WT & CT & HHS & $\mathbf{A P}$ & QC & PS \\
\hline HHS7 & 0.380 & 0.348 & 0.419 & 0.769 & 0.214 & 0.405 & 0.493 \\
\hline HHS9 & 0.442 & 0.456 & 0.456 & 0.836 & 0.339 & 0.445 & 0.550 \\
\hline HHS10 & 0.455 & 0.327 & 0.459 & 0.788 & 0.385 & 0.477 & 0.554 \\
\hline APS1 & 0.558 & 0.701 & 0.468 & 0.443 & 0.761 & 0.475 & 0.495 \\
\hline APS2 & 0.606 & 0.573 & 0.506 & 0.463 & 0.875 & 0.532 & 0.522 \\
\hline APS3 & 0.421 & 0.434 & 0.381 & 0.338 & 0.771 & 0.321 & 0.377 \\
\hline APS4 & 0.439 & 0.445 & 0.377 & 0.335 & 0.833 & 0.332 & 0.367 \\
\hline APS5 & 0.689 & 0.684 & 0.577 & 0.504 & 0.907 & 0.561 & 0.606 \\
\hline QC1 & 0.593 & 0.442 & 0.531 & 0.458 & 0.489 & 0.877 & 0.718 \\
\hline QC2 & 0.577 & 0.489 & 0.518 & 0.461 & 0.492 & 0.836 & 0.659 \\
\hline QC3 & 0.481 & 0.321 & 0.485 & 0.454 & 0.331 & 0.799 & 0.641 \\
\hline QC4 & 0.695 & 0.603 & 0.638 & 0.608 & 0.532 & 0.887 & 0.830 \\
\hline PS1 & 0.608 & 0.520 & 0.561 & 0.591 & 0.501 & 0.714 & 0.827 \\
\hline PS2 & 0.598 & 0.542 & 0.566 & 0.603 & 0.488 & 0.694 & 0.843 \\
\hline PS3 & 0.560 & 0.469 & 0.480 & 0.562 & 0.453 & 0.637 & 0.807 \\
\hline PS4 & 0.610 & 0.505 & 0.462 & 0.540 & 0.447 & 0.652 & 0.823 \\
\hline PS5 & 0.696 & 0.600 & 0.588 & 0.658 & 0.557 & 0.840 & 0.913 \\
\hline
\end{tabular}

Table 5. Cross-loadings results

Discriminant validity is also examined by comparing the square root of the AVE with correlations among constructs. The objective is to make sure that the square root of the AVE of each construct is greater than its correlations with other constructs (Fornell \& Larcker, 1981). The results are reported in Table 6. For all the latent variables the squares root of the AVE (diagonal values) were greater than the correlations with other latent variables. Therefore, the measurement model has adequate indicators' reliability, internal consistency, convergent validity, and discriminant validity.

\begin{tabular}{|c|c|c|c|c|c|c|c|}
\hline & PA & WT & CT & HHS & $\mathrm{AP}$ & QC & PS \\
\hline \multicolumn{8}{|c|}{ UPC model } \\
\hline PA & 0.819 & & & & & & \\
\hline WT & 0.798 & 0.865 & & & & & \\
\hline $\mathrm{CT}$ & 0.637 & 0.536 & 0.912 & & & & \\
\hline HHS & 0.693 & 0.624 & 0.671 & 0.804 & & & \\
\hline $\mathrm{AP}$ & 0.788 & 0.733 & 0.543 & 0.632 & 0.896 & & \\
\hline QC & 0.680 & 0.569 & 0.723 & 0.720 & 0.601 & 0.890 & \\
\hline PS & 0.732 & 0.639 & 0.694 & 0.736 & 0.576 & 0.863 & 0.881 \\
\hline \multicolumn{8}{|c|}{ SPC model } \\
\hline PA & 0.832 & & & & & & \\
\hline WT & 0.781 & 0.843 & & & & & \\
\hline $\mathrm{CT}$ & 0.750 & 0.556 & 0.915 & & & & \\
\hline HHS & 0.631 & 0.564 & 0.600 & 0.788 & & & \\
\hline $\mathrm{AP}$ & 0.667 & 0.697 & 0.566 & 0.511 & 0.831 & & \\
\hline QC & 0.698 & 0.557 & 0.644 & 0.589 & 0.549 & 0.850 & \\
\hline PS & 0.731 & 0.628 & 0.633 & 0.702 & 0.583 & 0.839 & 0.843 \\
\hline
\end{tabular}

Table 6. Discriminant validity results 


\subsubsection{Hierarchical Model}

In this study, HL was specified as a second-order hierarchical reflective latent variable, comprising five first-order latent variables (PA, WT, CT, HHS, and AP). The HL variable received all the first-order latent variables' items. Table 7 presents the hierarchical structure of HL and the explained variance in its components.

\begin{tabular}{|c|c|c|c|c|c|c|}
\hline & Indices & PA & WT & CT & HHS & $\mathrm{AP}$ \\
\hline \multirow{3}{*}{ UPC model } & $\mathrm{R}^{2}$ & 0.866 & 0.744 & 0.549 & 0.757 & 0.737 \\
\hline & $\beta$ & 0.931 & 0.863 & 0.741 & 0.870 & 0.858 \\
\hline & $\mathrm{p}$ - value & $<0.001$ & $<0.001$ & $<0.001$ & $<0.001$ & $<0.001$ \\
\hline \multirow{3}{*}{ SPC model } & $\mathrm{R}^{2}$ & 0.827 & 0.778 & 0.599 & 0.640 & 0.667 \\
\hline & $\beta$ & 0.909 & 0.882 & 0.774 & 0.800 & 0.817 \\
\hline & $\mathrm{p}$-value & $<0.001$ & $<0.001$ & $<0.001$ & $<0.001$ & $<0.001$ \\
\hline
\end{tabular}

Table 7. HL Hierarchical model

\subsubsection{Structural Model}

The structural model was assessed by checking a set of indices as described by Hair et al. (2019): significance and relevance of the structural model relationships, coefficient of determination $\mathrm{R}^{2}$, effect size $\mathrm{f}^{2}$, and predictive relevance of the model $\mathrm{Q}^{2}$. The final two models UPC and SPC are provided in Figures 3 and 4 respectively.

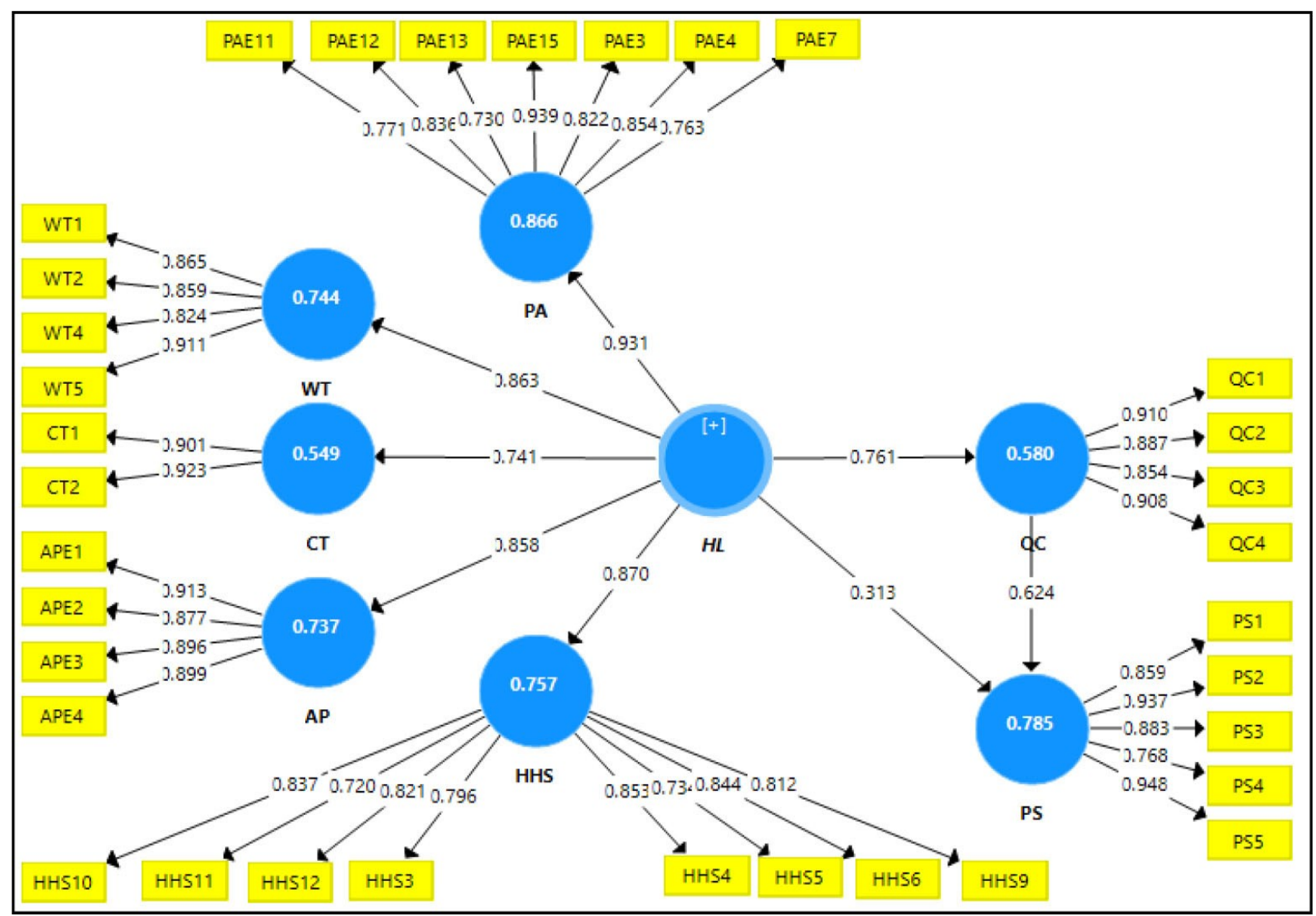

Figure 3. UPC final SEM-PLS model 


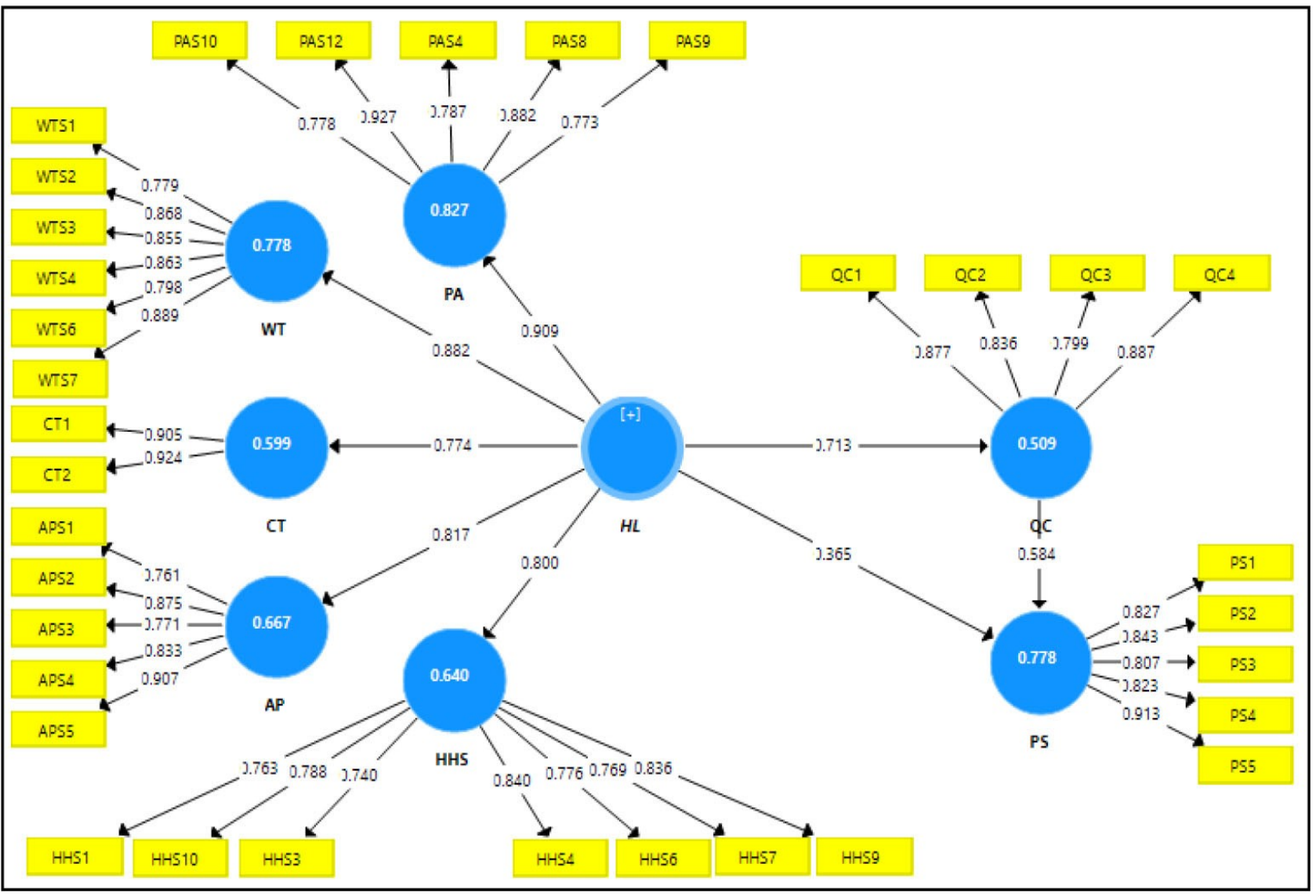

Figure 4. SPC final SEM-PLS model

Statistical significance and relevance of path coefficients: The execution of the PLS-SEM algorithm allows the estimation of the structural model path coefficients, and test the research hypotheses. However, the significance of a path coefficient ultimately depends on its standard deviation obtained by bootstrapping. Thus, a bootstrap of 5000 subsamples was performed (Hair et al., 2017). Table 8 presents the path coefficients of the three hypotheses and their standard deviations.

\begin{tabular}{|c|c|r|r|r|r|r|r|r|r|r|}
\hline \multirow{2}{*}{ Hypotheses } & \multirow{2}{*}{ Path } & \multicolumn{4}{|c|}{ UCP model } & \multicolumn{5}{|c|}{ SPC model } \\
\cline { 3 - 12 } & & $\begin{array}{c}\text { Standard } \\
\text { Beta }\end{array}$ & $\begin{array}{c}\text { Standard } \\
\text { Error }\end{array}$ & t-value & p-value & $\begin{array}{c}\text { Standard } \\
\text { Beta }\end{array}$ & $\begin{array}{c}\text { Standard } \\
\text { Error }\end{array}$ & t-value & p-value & Conclusion \\
\hline H1 & QC $\rightarrow$ PS & 0.624 & 0.050 & 12.552 & $<0.001$ & 0.584 & 0.062 & 9.424 & $<0.001$ & Accepted** \\
\hline H2 & HL $\rightarrow$ QC & 0.761 & 0.029 & 26.052 & $<0.001$ & 0.713 & 0.043 & 16.485 & $<0.001$ & Accepted** \\
\hline H3 & HL $\rightarrow$ PS & 0.313 & 0.052 & 6.028 & $<0.001$ & 0.365 & 0.064 & 5.685 & $<0.001$ & Accepted** \\
\hline
\end{tabular}

** significant at $\mathrm{p}$-value $<0.001$

Table 8. Bootstrapping results for hypotheses test

Coefficient of determination $\mathrm{R}^{2}$ : The coefficient of determination $\mathrm{R}^{2}$ is a commonly used measure for evaluating the structural model (Hüttinger, Schiele \& Schröer, 2014). It measures the explained variance in endogenous variables and is, therefore, a measure of the explanatory power of the model (Hair et al., 2019). Nevertheless, the $\mathrm{R}^{2}$ value depends on the number of exogenous variables. When the number of exogenous variables increases the $\mathrm{R}^{2}$ value of the endogenous variable automatically increases. For this reason, it is recommended to use the adjusted $R^{2}\left(R_{\text {adi }}^{2}\right)$ for endogenous variables with two or more exogenous latent variables (Hair et al., 2017). $\mathrm{R}^{2}$ values of $0.75,0.50$ or 0.25 are considered substantial, moderate and weak respectively (Hair et al., 2019). Table 9 reports the $\mathrm{R}^{2}$ and $\mathrm{R}_{\text {adj }}^{2}$ values of the endogenous variables of the two models. In the UCP model, 58\% and $78.4 \%$ of the respective 
variances of the variables QC and PS are explained by the exogenous variable HL. These values are $50.9 \%$ and $77.5 \%$ for the SPC model.

Effect size $f$ : As underlined above the $\mathrm{R}^{2}$ value increases as the number of exogenous variables increases, it is then suggested to evaluate the impact of the removal of each exogenous variable on the endogenous variable using the effect size $\mathrm{f}^{2}$. This parameter allows specifying if the removal of an exogenous variable has an impact on the endogenous latent variable. $\mathrm{f}^{2}$ values of $0.02,0.15$ and 0.35 Indicate, respectively, small, medium and large effect of the exogenous variable (Hair et al., 2019). Models in Figures 3 and 4 show that the endogenous variable PS has two exogenous variables: HL and QC. Table 10 presents the effect size of the removal of each of these two exogenous variables on the endogenous variable.

Blindfolding and predictive relevance $Q^{2}$ : The $\mathrm{Q}^{2}$ is another mean to assess the model's predictive accuracy. It is based on the blindfolding procedure, which consists of deleting individual data points of latent variables' indicators and estimating the model parameters based on the remaining data. Using these estimates as inputs, the blindfolding procedure predicts the original values of data points that have been deleted. The differences between the predicted values and the original values are used to calculate the $\mathrm{Q}^{2}$ value. As a rule of thumb $\mathrm{Q}^{2}$ values greater than $0,0.25$ and 0.50 illustrate small, medium and large predictive relevance of the model (Hair et al., 2019). The $\mathrm{Q}^{2}$ values of the two endogenous variables QC and PS, using an omitted distance $\mathrm{D}=7$, are given in Table 11. These results support the predictive power of the model.

\begin{tabular}{|c|c|c|c|c|c|}
\hline \multirow{2}{*}{$\begin{array}{l}\text { Endogenous } \\
\text { variables }\end{array}$} & \multicolumn{2}{|c|}{ UPC model } & \multicolumn{2}{|c|}{ SPC model } & \multirow{2}{*}{ Results } \\
\hline & $\mathbf{R}^{2}$ & $\mathbf{R}^{2}{ }_{a d j}$ & $\mathbf{R}^{2}$ & $\mathbf{R}^{2}{ }_{a j j}$ & \\
\hline QC & 0.580 & - & 0.509 & - & Moderate \\
\hline PS & 0.785 & 0.784 & 0.778 & 0.775 & Substantial \\
\hline
\end{tabular}

Table 9. Coefficients of determination $\mathrm{R}^{2}$ and $\mathrm{R}_{\text {adj }}^{2}$

\begin{tabular}{|c|c|c|c|}
\hline \multirow{2}{*}{ Exogenous variables } & UPC model & SPC model & \multirow{2}{*}{ Results } \\
\hline & $f^{2}$ & $\mathrm{f}^{2}$ & \\
\hline HL & 0.192 & 0.295 & Medium effect size \\
\hline QC & 0.764 & 0.754 & Large effect size \\
\hline
\end{tabular}

Table 10. Effect size $\mathrm{f}^{2}$ of the exogenous variables

\begin{tabular}{|c|c|c|c|c|c|c|c|}
\hline \multirow{2}{*}{$\begin{array}{c}\text { Endogenous } \\
\text { variables }\end{array}$} & \multicolumn{3}{|c|}{ UPC model } & \multicolumn{3}{c|}{ SPC model } & \multirow{2}{*}{ Results } \\
\cline { 2 - 8 } & SSO & SSE & $Q^{2}$ & SSO & SSE & $Q^{2}$ & \\
\hline QC & 940.000 & 516.179 & 0.451 & 596.000 & 382.137 & 0.359 & Medium predictive relevance \\
\hline PS & 1175.000 & 473.764 & 0.597 & 745.000 & 339.168 & 0.545 & Large predictive relevance \\
\hline
\end{tabular}

SSO: the sum of the squared observations, SEE: the sum of the squared prediction errors

Table 11. Blindfolding results

\subsubsection{Mediating Effect}

In the developed model, HL and PS are connected by two paths (Figure 5): direct path HL $\rightarrow$ PS and indirect path $\mathrm{HL} \rightarrow \mathrm{QC} \rightarrow \mathrm{PS}$. In the indirect path, the variable QC is considered as a mediator variable. Hence, it is necessary to test the relevance of this mediation. In this regard, we followed steps described by Hair, Hult, Ringle, and Sarstedt (2014). First, we checked the significance of the direct effect HL $\rightarrow$ PS, without the introduction of the mediator variable QC. Second, we included the mediator variable QC and examined the significance of the indirect effect. Finally, we assessed the strength of the mediation by calculating the variance accounted for (VAF) value. All of these steps were performed by applying a bootstrapping of 5000 subsamples (Hair et al., 2014). 
The results, for the UPC model, showed that the direct effect HL $\rightarrow$ PS has a coefficient $\beta=0.787(t=29.715)$, and therefore it is a significant effect. After the introduction of the mediator variable QC, we obtained a coefficient $\beta_{2}=0.761(t=25.929)$ for the effect $\mathrm{HL} \rightarrow \mathrm{QC}$ and $\beta_{3}=0.624(\mathrm{t}=12.321)$ for the effect $\mathrm{QC} \rightarrow \mathrm{PS}$. Consequently, the indirect effect $\mathrm{HL} \rightarrow \mathrm{QC} \rightarrow \mathrm{PS}$ has a coefficient $\beta_{2} \times \beta_{3}=0.475$ ( $\left.\mathrm{t}=11.688\right)$, which is significant. The inclusion of the mediator variable $Q C$ has increased the $\mathrm{R}^{2}$ value of the endogenous variable PS from 0.619 ( $\left.\mathrm{t}=14.955\right)$ to 0.785 $(t=33.573)$. Also, the coefficient of the direct effect $H L \rightarrow P S$ decreased from $\beta=0.787(t=29.715)$ to $\beta_{1}=0.313$ $(t=6.028)$. Thus, the mediator effect absorbed some of the direct effects. The absorbed proportion is calculated by the VAF value, which indicates the size of the indirect effect in relation to the total effect. The VAF value is 0.603 , which leads to the conclusion that the indirect effect explained $60.3 \%$ of the total effect (Figure 5). Therefore, the mediating effect of QC is partial as the VAF score is between $20 \%$ and $80 \%$ (Hair et al., 2014). It is a complementary mediation since the product of the three path coefficients $\beta_{1}, \beta_{2}$ and $\beta_{3}$ is positive (Hair et al., 2014). For the SPC model, the same analysis was conducted. The results are shown in Figure 5.

\begin{tabular}{|c|c|c|c|c|c|c|}
\hline \multirow[b]{2}{*}{ Path } & \multicolumn{3}{|c|}{ UPC model } & \multicolumn{3}{|c|}{ SPC model } \\
\hline & $\begin{array}{l}\text { Path } \\
\text { coefficient }\end{array}$ & t-statistics & p-value & $\begin{array}{l}\text { Path } \\
\text { coefficient }\end{array}$ & t-statistics & p-value \\
\hline $\begin{array}{l}\beta: H L \rightarrow \text { PS } \\
\text { (without mediator variable) }\end{array}$ & 0.787 & 29.715 & $<0.001$ & 0.780 & 20.087 & $<0.001$ \\
\hline $\begin{array}{l}\beta_{1}: H L \rightarrow \text { PS } \\
\text { (with mediator variable) }\end{array}$ & 0.313 & 6.028 & $<0.001$ & 0.365 & 5.542 & $<0.001$ \\
\hline$\beta_{2}: \mathrm{HL} \rightarrow \mathrm{QC}$ & 0.761 & 25.929 & $<0.001$ & 0.713 & 16.541 & $<0.001$ \\
\hline$\beta_{3}: \mathrm{QC} \rightarrow \mathrm{PS}$ & 0.624 & 12.321 & $<0.001$ & 0.584 & 9.151 & $<0.001$ \\
\hline$\beta_{2} \times \beta_{3}$ & 0.475 & 11.688 & $<0.001$ & 0.416 & 9.616 & $<0.001$ \\
\hline $\operatorname{VAF}\left(=\frac{\beta 2 \times \beta 3}{\beta 2 \times \beta 3+\beta 1}\right)$ & & & 0.603 & & & 0.533 \\
\hline
\end{tabular}

Figure 5. Mediating effect analysis

\section{Discussion}

This study reports the results of the first study concerning the examination of the relationship between HL, QC, and PS. It represents one of the first attempts to develop a structured model to empirically examine the effect of HL on both QC and PS. Up to now, there has been little in-depth analysis especially quantitative studies in this research area; therefore, our study helps to partially fill this knowledge gap.

In order to test the research's hypotheses, which stipulate the existence of an influential relationship between HL, QC, and PS, a survey was conducted among hospitalized patients in three public healthcare facilities located in the city of Fez-Morocco. Collected data were analyzed using the SEM method, which remains the most widely used method for testing and validating research hypotheses in the social sciences area. Results revealed a significant influence of HL on QC and PS. Thus, the research hypotheses are all confirmed and validated. Further, the proposed model leads to the conclusion that HL contributes to explaining more than $50 \%$ and $70 \%$ respectively of the variance in the QC and PS. In the proposed model, HL was specified as a second-order latent variable, composed of first-order latent variables, namely: PA, WT, CT, HHS, and AP.

Statistical analysis showed that the variable PA is the most preponderant component of HL. Its path coefficient is the highest exceeding 0.900: $\beta=0.931$ ( $p$-value $<0.001$ ) for the UPC model and $\beta=0.909$ ( $p$-value $<0.001$ ) for the 
SPC model. In the Moroccan context, this result is far from being surprising. Health officials and researchers recognize that accessibility of care and particularly PA remains the major concern of the health system (Bouhaddou et al., 2013). Indeed, the household panel survey indicated that only $76.1 \%$ of sick people seek healthcare. In other words, one sick person out of four did not use healthcare services (ONDH, 2015). Also, the National Population and Family Health Survey denoted that almost $14 \%$ of women did not use healthcare services for childbirth (Ministry of Health, 2018). The same survey revealed that about $15 \%$ of elderly people requiring medical examinations did not seek healthcare because of PA difficulties. This was explained by many factors, including geographical remoteness, insufficient human resources, problems with the supply of medicines, under-equipment of healthcare facilities, inadequate medical transportation, etc. (Ministry of Health, 2018; The World Bank, 2015).

According to the UPC model results, special attention should be paid to the accessibility of medical transportation and the availability of technical equipment/facilities, as these elements showed strong correlations with the PA. These findings are in line with other studies and official reports that have reported the issue of medical transportation in Morocco (Frichi, Ben Kacem, Jawab, Kamach \& Chafik, 2020; Hssain \& Hssain, 2013; Tachfouti, Bhatti, Nejjari, Kanjaa \& Salmi, 2011), and the low availability of technical facilities (CESE, 2013).

As for the SPC model, two elements showed strong correlations with the PA. The first is the availability of medical and nursing staff. This can be explained by the critical shortage of physicians and nurses in Morocco (Ministry of Health, 2012). Moreover, the health workforce shortfall is exacerbated by the unbalanced distribution of physicians and nurses across the country, which highlights the shortcomings of the human resources management system (CESE, 2013). The second element is the availability of support and guidance staff, whose role is to guide, assist and help patients moving smoothly between care units. This is in accordance with the findings of previous research, which indicated that difficulties in patient movements inside healthcare facilities caused patient dissatisfaction (Obtel, El Achhab, Bendahhou, Benider, Errihani, Zidouh et al., 2012).

The second and third components of HL with high path coefficients are different depending on the admission mode. In the UCP model, for patients admitted through the emergency department, the second component is HHS $(\beta=0.870 ; \mathrm{p}$-value $<0.001)$ and the third is WT $(\beta=0.863$; $\mathrm{p}$-value $<0.001)$. In the SPC model, for scheduled patients, the second component is WT $(\beta=0.882$; $\mathrm{p}$-value $<0.001)$ followed by AP $(\beta=0.817$; $\mathrm{p}$-value $<0.001)$. This difference is explained by the hospital admission type. In fact, urgent patients wait less than scheduled patients to receive care; they are prioritized because they require rapid medical intervention. In addition, the preparation and constitution of administrative files are carried out downstream of the care process. In contrast, planned patients are required to complete the administrative procedures upstream of the admission process, and therefore they experience delays. Regarding the HHS, scheduled patients are admitted in prepared conditions: rooms and hospital beds are available, waiting areas and examination rooms are less crowded and therefore cleaner, etc. In general, HHS are not a major concern for scheduled patients comparing to difficulties related to WT and AP. On the other hand, urgent patients are often confronted with a lack of resources, particularly in terms of places (hospital rooms and beds), as their admission is not planned and therefore takes place without preparation. Likewise, waiting areas and examination rooms are overcrowded, resulting in a lack of cleanliness, available chairs in waiting areas, etc.

Several patient satisfaction surveys conducted in Morocco support the results of this study. Damghi, Belayachi, Armel, Zekraoui, Madani, Abidi et al. (2013), in their survey in an emergency department of a public hospital in Morocco, found a significant correlation between WT and PS. Their results also indicated that urgent patients perceived the WT more favorably than non-urgent patients. WT, as a predictor of dissatisfaction, was also reported by Kasouati, Bouti, Zidouh, Abd El Hamid, Boufaresse and Mrabet (2015). A study by Amazian, Toughrai, Benmansour, Laalim, El Alami and Mazaz, (2013) conducted in Fez University Hospital revealed high satisfaction rates, explained in particular by the hotel comfort. Nevertheless, almost half of the surveyed patients made negative judgments concerning AP. Another more recent survey at Fez University Hospital showed that a significant proportion of surveyed patients complained about appointment delays, WT, HHS and the complexity of AP (El Marnissi et al., 2019). 


\section{Conclusion}

Healthcare facilities are called upon to find new strategies to improve the quality of their services and patient satisfaction. There is general agreement that quality of care and patient satisfaction depend to a large extent on the performance of support activities. Indeed, medical acts can only be of high quality if the related logistics activities are managed and performed effectively. Thus, hospital logistics enhances healthcare accessibility and quality.

The objective of this study was to empirically examine the influence of hospital logistics on quality of care and patient satisfaction using the PLS-SEM method. The results showed a significant impact of hospital logistics on both quality of care and patient satisfaction. More specifically, among the five investigated components of hospital logistics, physical accessibility emerged as the most preponderant factor in both UPC and SPC models. Hence, improvement of physical accessibility would result in a significant increase in quality and satisfaction. It implies the availability and accessibility of medical transportation, support and guidance staff, medical and nursing staff, medical facilities and equipment, drug, etc. The coming together of all of these elements is a challenging issue. It requires optimal resources planning and management, effective synchronization of the various flows both within (between care units) and outside (with providers and stakeholders) healthcare facilities, etc.

Hospital logistics, as a performance lever, aims to rethink the entire health system by putting the patient at the center of activities. To ensure this, health policymakers and hospital managers should pay more interest and attention to logistics activities within hospitals.

Like most studies, this research has some limitations. First, its results cannot be generalized since the survey only concerned patients from three public healthcare facilities in the city of Fez. It didn't include patients from other Moroccan cities. Second, the components of hospital logistics in the model are restricted. They should be adapted and extended depending on the research scope and context. Third, the sample size is reduced because it was divided into two models. Therefore, the generalization of the results may be limited by these limitations.

Further studies in this area are encouraged. They should consider, in addition to the research limitations mentioned above, cultural and context specifies. The analysis of results may be used on some classification, such as providing information about the hospital type, number of beds, patients categories, etc.

\section{Declaration of Conflicting Interests}

The authors declared no conflicts of interest with respect to the research, authorship, and/or publication of this article.

\section{Funding}

The authors received no financial support for the research, authorship, and/or publication of this article.

\section{References}

Abu-Odah, H., Abu Salah, A., El-Khateeb, A., \& El-Nems, K. (2018). Patients' satisfaction towards medical services at the emergency department of European Gaza Hospital-Gaza Strip. Journal of Emergency Practice and Trauma, 4(2), 77-81. https://doi.org/10.15171/jept.2018.08

Ahmad, B.A., Khairatul, K., \& Farnaza, A. (2017). An assessment of patient waiting and consultation time in a primary healthcare clinic. Malaysian Family Physician: The Official Journal of the Academy of Family Physicians of Malaysia, 12(1), 14-21.

Akachi, Y., \& Kruk, M.E. (2017). Quality of care: measuring a neglected driver of improved health. Bulletin of the World Health Organization, 95(6), 465-472. https://doi.org/10.2471/BLT.16.180190

Al-Mhasnah, A.M., Salleh, F., Afthanorhan, A., \& Ghazali, P.L. (2018). The relationship between services quality and customer satisfaction among Jordanian healthcare sector. Management Science Letters, 8(12), 1413-1420. https://doi.org/10.5267/j.msl.2018.10.003 
Aljaberi, M.A., Juni, M.H., Al-Maqtari, R.A., Lye, M.S., Saeed, M.A., Al-Dubai, S.A.R. et al. (2018). Relationships among perceived quality of healthcare services, satisfaction and behavioural intentions of international students in Kuala Lumpur, Malaysia: a cross-sectional study. BMJ Open, 8(9), e021180. https://doi.org/10.1136/bmjopen-2017-021180

Amazian, K., Toughrai, I., Benmansour, N., Laalim, S. A., El Alami, M.E.A., \& Mazaz, K. (2013). Enquête de satisfaction des patients atteints de cancer dans un hôpital universitaire au Maroc. Sante Publique, 25(5), 627-632. https://doi.org/10.3917/spub.135.0627

Assefa, F., Mosse, A., \& Hailemichael, Y. (2011). Assessment of Clients' Satisfaction with Health Service Deliveries at Jimma University Specialized Hospital. Ethiopian Journal of Health Sciences, 21(2), 101-109. https://doi.org/10.4314/ejhs.v21i2.69050

Azzi, A., Persona, A., Sgarbossa, F., \& Bonin, M. (2013). Drug inventory management and distribution: outsourcing logistics to third-party providers. Strategic Outsourcing: An International Journal, 6(1), 48-64. https://doi.org/10.1108/17538291311316063

Badri, M.A., Attia, S., \& Ustadi, A.M. (2009). Healthcare quality and moderators of patient satisfaction: testing for causality. International Journal of Health Care Quality Assurance, 22(4), 382-410. https://doi.org/10.1108/09526860910964843

Badri, M.A., Dodeen, H., Al Khaili, M., \& Abdulla, M. (2005). Development of the National Inpatient Satisfaction Constructs and Items for the United Arab Emirates. International Journal of Applied Health Studies, 1(3), 1-22.

Barclay, D., Higgins, C., \& Thompson, R. (1995). The Partial Least Squares Approach to Causal Modeling: Personal Computer Adoption and Use as an Illustration, Technology Studies. Special Issue on Research Methodology, 2(2), 285-309.

Bautista, J.M.S., \& Tangsoc, J.C. (2016). Hospital Service Quality Assessment and Analysis: A Multi-Perspective Approach. DLSU Business \& Economics Review, 26(1), 30-49.

Beaulieu, M. (2019). Une expérience de collaboration logistique. Gestion Hospitalière, 585, 211-214.

Beaulieu, M., Bentahar, O., \& Benzidia, S. (2019). L’évolution de la logistique hospitalière - L'expérience du Québec. Gestion Hospitalière, 583, 94-97.

Beaulieu, M., \& Venne, J.-F. (2018). La logistique au coeur de la performance. Gestion, 43(3), 86-89. https://doi.org/10.3917/ riges.433.0086

Benamirouche, R. (2015). L'impact du système d'information hospitalier sur la qualité des soins. Revue d'Épidémiologie et de Santé Publique, 63, S29. https://doi.org/10.1016/j.respe.2015.01.068

Bleustein, C., Rothschild, D.B., Valen, A., Valaitis, E., Schweitzer, L., \& Jones, R. (2014). Wait Times, Patient Satisfaction Scores, and the Perception of Care. The American Journal of Managed Care, 20(5), 393-400.

Bouhaddou, O., Bennani Othmani, M., \& Diouny, S. (2013). Medical informatics in morocco. Yearbook of Medical Informatics, 22(1), 190-196. https://doi.org/10.1055/s-0038-1638855

Buntak, K., Kovačić, M., \& Martinčević, I. (2019). Impact of medical logistics on the quality of life of healthcare users. In Quality Festival 2019 (1025-1032). https://doi.org/10.24874/PES01.02.109

CESE. (2013). Les soins de santé de base Vers un accès équitable et généralisé. Available at: http://www.cese.ma/Documents/PDF/Rapport SSB VF.pdf

Chougrani, S., \& Ouhadji, S. (2014). Les questionnaires de sortie et la place des usagers dans le projet qualité à l'Etablissement hospitalier universitaire d'Oran. Santé Publique, 26(4), 499-508.

https://doi.org/10.3917/spub.144.0499

Chow, G., \& Heaver, T. (1994). Logistics in the Canadian health care industry. Canadian Logistics Journal, 1(1), $29-73$. 
Churchill, G.A. (1979). A Paradigm for Developing Better Measures of Marketing Constructs. Journal of Marketing Research, 16(1), 64-73. https://doi.org/10.2307/3150876

Costin, M. (2010). Logistique hospitalière, un outil du management: le cas des hôpitaux français et moldaves. Humanisme et Entreprise, 299(4), 29-48. https:/ / doi.org/10.3917/ hume.299.0029

Dagger, T.S., \& Sweeney, J.C. (2007). Service quality attribute weights: How do novice and longer-term customers construct service quality perceptions? Journal of Service Research, 10(1), 22-42. https://doi.org/10.1177/1094670507303010

Damghi, N., Belayachi, J., Armel, B., Zekraoui, A., Madani, N., Abidi, K. et al. (2013). Patient satisfaction in a Moroccan emergency department. International Archives of Medicine, 6(1), 20. https://doi.org/10.1186/1755-7682-620

De Carvalho, P.P.S., Kalid, R.D.A., \& Rodriguez, J.L.M. (2019). Evaluation of the City Logistics Performance Through Structural Equations Model. IEEE Access, 7, 121081-121094. https://doi.org/10.1109/ACCESS.2019.2934647

Derebe, M.M., Shiferaw, M.B., \& Ayalew, M.A. (2017). Low satisfaction of clients for the health service provision in West Amhara region, Ethiopia. PLOS ONE, 12(6), 1-10. https://doi.org/10.1371/journal.pone.0179909

Donabedian, A. (2003). An Introduction to Quality Assurance in Health Care. Bashshur, R. (Ed.). New York: Oxford University Press.

Duggirala, M., Rajendran, C., \& Anantharaman, R.N. (2008). Patient-perceived dimensions of total quality service in healthcare. Benchmarking: An International Journal, 15(5), 560-583.

https://doi.org/10.1108/14635770810903150

El Marnissi, B., Abbass, F., Charaka, H., Mouhoute, N., Tritha, A., Bouhafa, T. et al. (2019). Evaluation of Cancer Patient Satisfaction: A Transversal Study in Radiotherapy Department, Hassan II University Hospital, Fez, Morocco. Advances in Public Health. https://doi.org/10.1155/2019/6430608

Errassafi, M., Abbar, H., \& Benabbou, Z. (2019). The mediating effect of internal integration on the relationship between supply chain integration and operational performance: evidence from Moroccan manufacturing companies. Journal of Industrial Engineering and Management, 12(2), 254-273. https://doi.org/10.3926/jiem.2794

Fang, J., Liu, L., \& Fang, P. (2019). What is the most important factor affecting patient satisfaction - A study based on gamma coefficient. Patient Preference and Adherence, 13, 515-525. https://doi.org/10.2147/PPA.S197015

Fornell, C., \& Larcker, D.F. (1981). Evaluating Structural Equation Models with Unobservable Variables and Measurement Error. Journal of Marketing Research, 18(1), 39-50. https://doi.org/10.1177/002224378101800104

Frichi, Y., Ben Kacem, A., Jawab, F., Kamach, O., \& Chafik, S. (2020). Improving Interhospital Medical Patient Transportation in Morocco: A Forcasting Collaborative Approach. In Euchi, J. (Ed.), Transportation, Logistics, and Supply Chain Management in Home Healthcare: Emerging Research and Opportunities (136-162). Pennsylvania, USA: IGI Global. https://doi.org/10.4018/978-1-7998-0268-6.ch008

Frichi, Y., Jawab, F., \& Boutahari, S. (2018). Patient satisfaction factors and their correspondence with hospital logistics activities. In Proceedings of the International Conference on Industrial Engineering and Operations Management (1141-1147). Paris, France: IEOM Society International.

Frichi, Y., Jawab, F., \& Boutahari, S. (2019a). An Exploratory Qualitative Study of the Influence of Hospital Logistics Factors on Quality of Care and Patient Satisfaction at Public Hospitals in Morocco. Advances in Science, Technology and Engineering Systems Journal, 4(6), 414-422. https:/ / doi.org/10.25046/aj040652 
Frichi, Y., Jawab, F., \& Boutahari, S. (2019b). SEM to analyze the interaction between hospital logistics and quality of care, a systematic review. In International Colloquium on Logistics and Supply Chain Management, LOGISTIQUA 2019. IEEE. https://doi.org/10.1109/LOGISTIQUA.2019.8907313

Frichi, Y., Jawab, F., \& Boutahari, S. (2019c). The Mixed-Method 5W2D Approach for Health System Stakeholders Analysis in Quality of Care: An Application to the Moroccan Context. International Journal of Environmental Research and Public Health, 16(16), 2899. https://doi.org/10.3390/ijerph16162899

Frichi, Y., Jawab, F., Boutahari, S., Zehmed, K., Moufad, I., Akoudad, K. et al. (2018). Hospital logistics: An effective tool in improving the quality of care. In Proceedings of the International Conference on Industrial Engineering and Operations Management. Paris, France.

Frosch, D.L. (2015). Patient-Reported Outcomes as a Measure of Healthcare Quality. Journal of General Internal Medicine, 30(10), 1383-1384. https://doi.org/10.1007/s11606-015-3476-2

Hair, J.F., Hult, G.T.M., Ringle, C.M., \& Sarstedt, M. (2014). A Primer on Partial Least Squares Structural Equation Modeling (PLS-SEM). Los Angeless: SAGE Publications. https://doi.org/10.1016/j.lrp.2013.01.002

Hair, J.F., Hult, G.T.M., Ringle, C.M., \& Sarstedt, M. (2017). A Primer on Partial Least Squares Structural Equation Modeling (PLS-SEM) (2nd ed.). Los Angeles: SAGE Publications, Inc.

Hair, J.F., Risher, J.J., Sarstedt, M., \& Ringle, C.M. (2019). When to use and how to report the results of PLS-SEM. European Business Review, 31(1), 2-24. https://doi.org/10.1108/EBR-11-2018-0203

Halsdorfer, N.D., Blasquez, J., Bensoussan, L., Gentile, S., Collado, H., Viton, J.M. et al. (2011). An assessment of patient satisfaction for a short-stay program in a physical and rehabilitation medicine day hospital. Annals of Physical and Rehabilitation Medicine, 54(4), 236-247. https://doi.org/10.1016/j.rehab.2011.04.001

Howie, J.G.R., Porter, M.D., Heaney, D.J., \& Hopton, J.L. (1991). Long to short consultation ratio: a proxy measure of quality of care for general practice. British Journal of General Practice, 41(343), 48-54.

Hssain, H., \& Hssain, I. (2013). la régulation Médicale et la stratégie De Mise à niveau Des urgences au Maroc. Mediterranean Journal of Emergency Medicine, 17, 26-30.

Hussain, A., Asif, M., Jameel, A., \& Hwang, J. (2019). Measuring OPD Patient Satisfaction with Different Service Delivery Aspects at Public Hospitals in Pakistan. International Journal of Environmental Research and Public Health, 16(13), 2340. https://doi.org/10.3390/ijerph16132340

Hüttinger, L., Schiele, H., \& Schröer, D. (2014). Exploring the antecedents of preferential customer treatment by suppliers: A mixed methods approach. Supply Chain Management: An International Journal, 19(5/6), 697-721. https://doi.org/10.1108/SCM-06-2014-0194

Jang, A.R., \& Jang, K.S. (2017). Structural Equation Modeling on Health-related Quality of Life of Patients with Ankylosing Spondylitis. Iranian Journal of Public Health, 46(10), 1338-1346.

Jawab, F., Frichi, Y., \& Boutahari, S. (2018). Hospital Logistics Activities. In International Conference on Industrial Engineering and Operations Management. Bandung, Indonesia.

Jobin, M.-H., Beaulieu, M., \& Boivin, A. (2004). Gérer la performance de la logistique hospitalière. Logistique \& Management, 12(sup1), 21-30. https://doi.org/10.1080/12507970.2004.11516815

Johnson, D.M., \& Russell, R.S. (2015). SEM of service quality to predict overall patient satisfaction in medical clinics: A case study. Quality Management Journal, 22(4), 18-36. https://doi.org/10.1080/10686967.2015.11918448

Kashkoli, S.A., Zarei, E., Daneshkohan, A., \& Khodakarim, S. (2017). Hospital responsiveness and its effect on overall patient satisfaction: A cross-sectional study in Iran. International Journal of Health Care Quality Assurance, 30(8), 728-736. https://doi.org/10.1108/IJHCQA-07-2016-0098 
Kasouati, J., Bouti, L., Zidouh, O., Abd El Hamid, Z., Boufaresse, A., \& Mrabet, M. (2015). Évaluation de la satisfaction des patients de la prise en charge de la douleur au service des urgences de l'Hôpital Militaire d'Instruction Mohamed V, Rabat, Maroc. Revue d'Épidémiologie et de Santé Publique, 63, S75.

https://doi.org/10.1016/j.respe.2015.03.085

Kline, R.B. (2011). Principles and Practice of Structural Equation Modeling (3rd ed.). The Guilford Press.

Kriegel, J., Jehle, F., Dieck, M., \& Mallory, P. (2013). Advanced services in hospital logistics in the German health service sector. Logistics Research, 6(2-3), 47-56. https://doi.org/10.1007/s12159-013-0100-x

Kwon, I.W.G., Kim, S.H., \& Martin, D.G. (2016). Healthcare supply chain management; strategic areas for quality and financial improvement. Technological Forecasting and Social Change, 113, 422-428.

https://doi.org/10.1016/j.techfore.2016.07.014

Landry, S., \& Beaulieu, M. (2002). La logistique hospitalière: un remède aux maux du secteur de la santé? Gestion, 26(4), 34-41. https://doi.org/10.3917/riges.264.0034

Landry, S., \& Beaulieu, M. (2013). The Challenges of Hospital Supply Chain Management, from Central Stores to Nursing Units. In Springer (Ed.), Handbook of Healthcare Operations Management-Methods and Applications, 184, 465-482. New York. https://doi.org/10.1007/978-1-4419-6151-8

Landry, S., \& Philippe, R. (2004). How logistics can service healthcare. Supply Chain Forum: An International Journal, 5(2), 24-30. https://doi.org/10.1080/16258312.2004.11517130

Lerebours, F., Saltel, P., Béthune-volters, A., Nallet, G., Bourdat, P., Vesin-etterlen, F. et al. (2015). Satisfaction des patientes traitées par chimiothérapie en hôpital de jour pour un cancer du sein: résultats de l'enquête TemporELLES. Bulletin Du Cancer, 102(4), 316-323. https://doi.org/10.1016/j.bulcan.2015.01.011

Lobo, A., Duarte, P., Carvalho, A., Rodrigues, V., Monteiro, J.M., \& Alves, H. (2014). The Association of Equity, Accessibility, and Price With Primary Healthcare User's Satisfaction. Western Journal of Nursing Research, 36(2), 191-208. https://doi.org/10.1177/0193945913497830

Lohr, K.N., \& Schroeder, S.A. (1990). A strategy for quality assurance in medicare. The New England Journal of Medicine, 322(10), 707-712. https://doi.org/10.1056/NEJM199003083221031

Marama, T., Bayu, H., Merga, M., \& Binu, W. (2018). Patient Satisfaction and Associated Factors among Clients Admitted to Obstetrics and Gynecology Wards of Public Hospitals in Mekelle Town, Ethiopia: An InstitutionBased Cross-Sectional Study. Obstetrics and Gynecology International. https://doi.org/10.1155/2018/2475059

Más, A., Parra, P., Bermejo, R., Hidalgo, M., \& Calle, J. (2016). Improving quality in healthcare: What makes a satisfied patient? Revista de Calidad Asistencial, 31(4), 196-203. https://doi.org/10.1016/j.cali.2015.11.006

Meena, P.L., \& Sarmah, S.P. (2012). Development of a supplier satisfaction index model. Industrial Management \& Data Systems, 112(8), 1236-1254. https://doi.org/10.1108/IMDS-02-2016-0052

Melo, T. (2012). A note on challenges and opportunities for Operations Research in hospital logistics. Technical Reports on Logistics of the Saarland Business School, 2, 1-13.

Ministry of Health. (2012). Stratégie Sectorielle de Santé 2012-2016. Available at: http://www.sante.gov.ma/Docs/Documents/secteur santé.pdf

Ministry of Health. (2018). Enquête Nationale sur la Population et la Santé Familiale (ENPSF). Rabat, Morocco.

Mohamed, B., \& Azizan, N.A. (2015). Perceived service quality's effect on patient satisfaction and behavioural compliance. International Journal of Health Care Quality Assurance, 28(3), 300-314. https://doi.org/10.1108/IJHCQA06-2014-0074

Mohd, A., \& Chakravarty, A. (2014). Patient satisfaction with services of the outpatient department. Medical Journal Armed Forces India, 70(3), 237-242. https://doi.org/10.1016/j.mjafi.2013.06.010 
Moons, K., Waeyenbergh, G., \& Pintelon, L. (2019). Measuring the logistics performance of internal hospital supply chains - a literature study. Omega (United Kingdom), 82, 205-217. https://doi.org/10.1016/j.omega.2018.01.007

Moufad, I., \& Jawab, F. (2019). A study framework for assessing the performance of the urban freight transport based on PLS approach. Archives of Transport, 49(1), 69-85. https://doi.org/10.5604/01.3001.0013.2777

Munir, B.A., Hafeez, S., Rashid, S., Iqbal, R., \& Javed, M.A. (2019). Geospatial assessment of physical accessibility of healthcare and agent-based modeling for system efficacy. GeoJournal, 0123456789. https://doi.org/10.1007/s10708-019-09987-z

Narayana, S.A., Kumar Pati, R., \& Vrat, P. (2014). Managerial research on the pharmaceutical supply chain - A critical review and some insights for future directions. Journal of Purchasing \& Supply Management, 20(1), 18-40. https://doi.org/10.1016/j.pursup.2013.09.001

Nottingham, Q., Johnson, D.M., \& Russell, R. (2018). A multi-year SEM model predicting the impact of behavior attributes on overall patient satisfaction. International Journal of Quality \& Reliability Management. https://doi.org/10.1108/IJQRM-02-2018-0031

Nylenna, M., Bjertnaes, O., Saunes, I.S., \& Lindahl, A.K. (2015). What is Good Quality of Health Care? Professions and Professionalism, 5(1). https://doi.org/10.7577/pp.909

Obtel, M., El Achhab, Y., Bendahhou, K., Benider, A., Errihani, H., Zidouh, A. et al. (2012). Measuring patient satisfaction in Moroccan oncology institutions: EORTC IN-Patsat32 and satisfaction in Moroccan patient with cancer. Journal Africain Du Cancer, 4(1), 9-17. https://doi.org/10.1007/s12558-011-0185-6

ONDH. (2015). Enquête Panel de ménages 2012 - rapport des premiers résultats. Rabat.

Park, K., Park, J., Kwon, Y.D., Kang, Y., \& Noh, J.W. (2016). Public satisfaction with the healthcare system performance in South Korea: Universal healthcare system. Health Policy, 120(6), 621-629. https://doi.org/10.1016/j.healthpol.2016.01.017

Parks, R., Wigand, R.T., Bennani Othmani, M., Serhier, Z., \& Bouhaddou, O. (2019). Electronic health records implementation in Morocco: Challenges of silo efforts and recommendations for improvements. International Journal of Medical Informatics, 129, 430-437. https://doi.org/10.1016/j.ijmedinf.2019.05.026

Põlluste, K., Kallikorm, R., Meiesaar, K., \& Lember, M. (2012). Satisfaction with access to health services: The perspective of Estonian patients with rheumatoid arthritis. The Scientific World Journal. https://doi.org/10.1100/2012/257569

Raposo, M.L., Alves, H.M., \& Duarte, P.A. (2009). Dimensions of service quality and satisfaction in healthcare: A patient's satisfaction index. Service Business, 3(1), 85-100. https://doi.org/10.1007/s11628-008-0055-1

Roussel, P., \& Wacheux, F. (2005). Management des ressources humaines. Méthodes de recherche en sciences humaines et sociales. De Boeck Supérieur, «Méthodes \& Recherches». https://doi.org/10.3917/dbu.rouss.2005.01

Sarstedt, M., \& Cheah, J.-H. (2019). Partial least squares structural equation modeling using SmartPLS: a software review. Journal of Marketing Analytics, 1. https://doi.org/10.1057/s41270-019-00058-3

Schmalbach, J.C.V., \& Avila, F.J.M. (2018). Structural equation models applied for evaluating service quality and satisfaction in the healthcare system of Cartagena de Indias D. T. Y C. (Colombia). Economics and Sociology, 11(2), 200-215. https://doi.org/10.14254/2071-789X.2018/11-2/14

Sevin, H.D. (2018). Hotel Services In Hospitals. Journal of Tourism and Gastronomy Studies, 6(1), 451-459. https://doi.org/10.21325/jotags.2018.198

Soares, J.B., Marinho, A.S., Fernandes, D., Moreira Gonçalves, B., Camila-Dias, C., Gonçalves, R. et al. (2015). Assessing overall patient satisfaction in inflammatory bowel disease using structural equation modeling. European Journal of Gastroenterology \& Hepatology, 27(8), 941-950. https://doi.org/10.1097/MEG.0000000000000385 
Soufi, G., Belayachi, J., Himmich, S., Ahid, S., Soufi, M., Zekraoui, A. et al. (2010). Patient satisfaction in an acute medicine department in Morocco. BMC Health Services Research, 10(1), 149. https://doi.org/10.1186/1472-6963-10149

Suess, C., \& Mody, M.A. (2018). Hotel-like hospital rooms' impact on patient well-being and willingness to pay: An examination using the theory of supportive design. International Journal of Contemporary Hospitality Management, 30(10), 3006-3025. https://doi.org/10.1108/IJCHM-04-2017-0231

Symmank, C., Krause, J., \& Gurtner, S. (2015). Stakeholder Variety in Healthcare and Their Integration in the Medical Device Development Process. In Gurtner, S., \& Soyez, K. (Eds.), Challenges and Opportunities in Health Care Management (247-258). Springer. https://doi.org/10.1007/978-3-319-12178-9

Tachfouti, N., Bhatti, J.A., Nejjari, C., Kanjaa, N., \& Salmi, L.R. (2011). Emergency trauma care for severe injuries in a Moroccan region: conformance to French and World Health Organization standards. Journal for Healthcare Quality, 33(1), 30-38. https://doi.org/10.1111/j.1945-1474.2010.00095.x

The World Bank (2015). Programme pour résultats d'amélioration de la santé primaire dans les zones rurales - Evaluation des systèmes de gestion environnementale et sociale.

Um, K.H., \& Lau, A.K.W. (2018). Healthcare service failure: how dissatisfied patients respond to poor service quality. International Journal of Operations and Production Management, 38(5), 1245-1270.

https://doi.org/10.1108/IJOPM-11-2016-0669

United Nations. (2015). Goal 3: Ensure healthy lives and promote well-being for all at all ages. Available at: https://www.un.org/sustainabledevelopment/health/ (Accesed: September 2019)

Verulava, T., Jorbenadze, R., Karimi, L., Dangadze, B., \& Barkalaia, T. (2018). Evaluation of Patient Satisfaction with Cardiology Services. The Open Public Health Journal, 11, 201-208. https://doi.org/10.2174/1874944501811010201

Villa, S., Barbieri, M., \& Lega, F. (2009). Restructuring patient flow logistics around patient care needs: implications and practicalities from three critical cases. Health Care Management Science, 12(2), 155-165. https://doi.org/10.1007/s10729-008-9091-6

Volland, J., Fügener, A., Schoenfelder, J., \& Brunner, J.O. (2017). Material logistics in hospitals: A literature review. Omega, 69, 82-101. https://doi.org/10.1016/j.omega.2016.08.004

WHO (2006). Quality of care: a process for making strategic choices in health systems. Geneva. https://doi.org/10.1542/peds.2010-1791

WHO (2008). Essential Environmental Health Standards in Health Care. Geneva, Switzerland. Available at: https://apps.who.int/iris/bitstream/handle/10665/43767/9789241547239 eng.pdf?sequence=1\&isAllowed=y

WHO (2012). WHO recommendations: Optimizing health worker roles to improve access to key maternal and newborn health interventions through task shifting. Geneva, Switzerland. Available at: https://apps.who.int/iris/bitstream/handle/10665/77764/9789241504843 eng.pdf? sequence $=1$

Journal of Industrial Engineering and Management, 2020 (www.jiem.org)

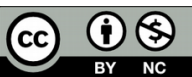

Article's contents are provided on an Attribution-Non Commercial 4.0 Creative commons International License. Readers are allowed to copy, distribute and communicate article's contents, provided the author's and Journal of Industrial Engineering and Management's names are included. It must not be used for commercial purposes. To see the complete license contents, please visit https://creativecommons.org/licenses/by-nc/4.0/. 